\title{
The Combined Extract of Black Sticky Rice and Dill Improves Poststroke Cognitive Impairment in Metabolic Syndrome Condition
}

\author{
Warin Ohnon $\mathbb{D}^{1},{ }^{1,2,3}$ Jintanaporn Wattanathorn $\left(\mathbb{D},{ }^{2,3,4}\right.$ Wipawee Thukham-mee, \\ Supaporn Muchimapura $\mathbb{D}^{2,3,4}$ Panakaporn Wannanon, ${ }^{2,3,4}$ and Terdthai Tong-un $\mathbb{D}^{2,3,4}$ \\ ${ }^{1}$ Department of Physiology and Graduate School (Neuroscience Program), Faculty of Medicine, Khon Kaen University, \\ Khon Kaen 40002, Thailand \\ ${ }^{2}$ Integrative Complementary Alternative Medicine Research and Development Center, Khon Kaen University, \\ Khon Kaen 40002, Thailand \\ ${ }^{3}$ Human High Performance and Health Promotion Research Institute, Khon Kaen University, Khon Kaen 40002, Thailand \\ ${ }^{4}$ Department of Physiology, Faculty of Medicine, Khon Kaen University, Khon Kaen 40002, Thailand
}

Correspondence should be addressed to Jintanaporn Wattanathorn; jinwat05@gmail.com

Received 1 September 2018; Revised 1 November 2018; Accepted 28 November 2018; Published 26 February 2019

Academic Editor: George Perry

Copyright @ 2019 Warin Ohnon et al. This is an open access article distributed under the Creative Commons Attribution License, which permits unrestricted use, distribution, and reproduction in any medium, provided the original work is properly cited.

\begin{abstract}
Despite the increase in cognitive deficit following stroke in metabolic syndrome (MetS) condition, the therapeutic strategy is still limited. Since oxidative stress and neuroinflammation play the crucial roles on the pathophysiology of aforementioned conditions, the cognitive enhancing effect of the combined extract of Oryza sativa and Anethum graveolens was considered based on their antioxidant, anti-inflammation, and neuroprotective effects together with the synergistic effect concept. Male Wistar rats weighing 180-220 g were induced metabolic syndrome-like condition by using a high-carbohydrate high-fat diet (HCHF diet). Then, reperfusion injury following cerebral ischemia was induced by the occlusion of right middle cerebral artery and treated with the combined extract of $O$. sativa and A. graveolens (OA extract) at doses of 0.5, 5, and $50 \mathrm{mg} / \mathrm{kg}$ BW once daily for 21 days. Spatial memory was assessed every 7 days throughout the experimental period. At the end of the study, neuron and glial fibrillary acidic protein- (GFAP-) positive cell densities, the oxidative stress status, AChE, and the expression of proinflammatory cytokines (TNF- $\alpha$, IL-6) in the hippocampus were determined. The results showed that OA extract at all doses used in this study significantly improved memory together with the reductions of MDA, TNF- $\alpha$, IL- 6 , AChE, and density of GFAP-positive cell but increased neuron density in the hippocampus. Taken together, OA is the potential cognitive enhancer in memory impairment following stroke in MetS condition. The possible underlying mechanism may occur partly via the reductions of oxidative stress status, GFAP-positive cell density, and neuroinflammatory cytokines such as TNF- $\alpha$ and IL-6 together with the suppression of AChE activity in the hippocampus. This study suggests that OA is the potential functional ingredient to improve the cognitive enhancer. However, further clinical research is required.
\end{abstract}

\section{Introduction}

Currently, the prevalence of metabolic syndrome (MetS), a cluster of metabolic disorders, is continually rising to $39-46 \%$ in every ethnic and age group [1]. It has been reported that this prevalence is increasing with the advanced age [2]. Accumulative lines of evidence during the last decade reveal that MetS is closely associated with stroke risk [3-5]. It has been demonstrated that the adjusted risk ratios for incident ischemic stroke associated with MetS are in the range of 2.1-2.47 [6-9]. Stroke is regarded as the important cause of disability. A high proportion of stroke survivors develop cognitive impairment within 3 months after stroke [10]. This defect produces the great impact on the quality of life of the patients. Accumulative lines of evidence demonstrate that oxidative stress imbalance and neuroinflammation play the 
crucial role on the pathophysiology of MetS, stroke, and cognitive impairment [11-16]. Based on the important role of both oxidative stress and inflammation mentioned earlier, they were considered as the target for neuroprotection.

According to the traditional folklore, food is served not only as a source of nutrients and energy but also as the tool for promoting health. Recently, food polyphenol intervention has been considered as the potential neuroprotection food. The recent study reveals that a polyphenol especially anthocyanin-rich diet can improve brain damage in an animal model of MetS induced by a high-carbohydrate high-fat diet via the attenuation of brain oxidative stress status [17] and inflammation [18]. Both Oryza sativa, L. indica (black sticky rice), and Anethum graveolens Linn. (dill) are commonly consumed in Thailand. They exhibit antioxidant $[19,20]$ and anti-inflammation effects $[21,22]$. In addition, they also possess neuroprotective effect [23-25]. Based on the pharmacological effects of both herbs mentioned earlier and a synergistic effect according to the traditional folklore, we hypothesized that the combined extract of black sticky rice and dill should provide neuroprotection against stroke in an animal model of MetS. Due to the lack of available data, we aimed to determine the neuroprotective of the combined extract of black sticky rice and dill against cerebral ischemia in an animal model of MetS induced by a high-carbohydrate high-fat diet ( $\mathrm{HCHF}$ diet). The possible underlying mechanisms were also explored.

\section{Materials and Methods}

2.1. Plant Material Preparation and Extraction. Oryza sativa, L. indica, and Anethum graveolens Linn. were collected from Khon Kaen Province. They were harvested during September-October. They were authenticated by Associate Panee Sirisa-ard, pharmacognosy expert from Faculty of Pharmacy, Chiang Mai University, who served as the consultant of High Human Performance and Health Promotion Research Institute, Khon Kaen University, Thailand. Voucher specimens (ICAM 12001 and ICAM12002) were deposited at Integrative Complementary Alternative Medicine Research and Development Center, Khon Kaen University. For the preparation, the grains of black sticky rice and aerial part of dill were cleaned and dried in the oven (Memmert $\mathrm{GmbH}, \mathrm{USA}$ ) at $60^{\circ} \mathrm{C}$ for 72 hours. Then, the water extract of black sticky rice and 95\% hydroalcoholic extract were prepared by using maceration technique. In brief, the plant materials mentioned earlier were subjected to the 24-hour maceration at room temperature. The extracts were harvested, centrifuged at $3000 \mathrm{rpm}$ for $10 \mathrm{~min}$, and filtered with Whatman no. 1 filter paper. The filtrates were collected and subjected to a freeze drying process. The percentage yields of $O$. sativa and A. graveolens were 10 and 26 , respectively. The yielded extracts were stored at $-20^{\circ} \mathrm{C}$ until use. The combination extract (OA extract) was prepared by mixing $O$. sativa and $A$. graveolens at a ratio of $1: 6$ based on our pilot data which showed that this ratio showed the highest potential for treating cerebral ischemia in metabolic syndrome.
2.2. Measurement of Total Phenolic Compound Contents. The total phenolic content of OA extract was determined by using the Folin-Ciocalteu colorimetric method. In brief, $1000 \mu \mathrm{l}$ of a 50\% Folin-Ciocalteu phenol reagent (Sigma-Aldrich, USA) and $158 \mu \mathrm{l}$ of distilled water were mixed with $20 \mu \mathrm{l}$ of the tested substances (OA extract and gallic acid) and incubated at $37^{\circ} \mathrm{C}$ for 8 minutes. At the end of the incubation period, $30 \mu \mathrm{l}$ of $20 \% \mathrm{Na}_{2} \mathrm{CO}_{3}$ (Sigma-Aldrich, USA) was added, mixed, and incubated at room temperature in the dark room for 2 hours. Then, the absorbance at $765 \mathrm{~nm}$ was recorded. Results were expressed as mg gallic acid equivalent (GAE)/mg per $0.1 \mathrm{~g}$ of OA extract. Various concentrations of gallic acid (Sigma-Aldrich, USA) ranging from 0 to $500 \mu \mathrm{g} / \mathrm{ml}$ were used to prepare the standard calibration curve [26].

2.3. Measurement of Flavonoid Content. The modified aluminium chloride colorimetric method was used to measure the flavonoid content of OA extract [27]. Aliquots of $1.5 \mathrm{ml}$ of the tested substances were added to equal volumes of a solution of $2 \% \mathrm{AlCl}_{3} \cdot 6 \mathrm{H}_{2} \mathrm{O}(2 \mathrm{~g}$ in $100 \mathrm{ml}$ methanol). Then, the mixture was subjected to a vigorous shake and incubated at room temperature for 30 minutes. At the end of the incubation period, an absorbance at $415 \mathrm{~nm}$ was measured. The contents of flavonoids were expressed as $\mu \mathrm{g}$ quercetin equivalent/mg extract.

\subsection{Antioxidant Property Assessment}

2.4.1. 1,1-Diphenyl-2-picryl-hydrazyl (DPPH) Radical Assay. This method measured an antioxidant activity of the tested substance on the basis of the scavenging activities of the stable 1,1-diphenyl-2-picrylhydrazyl (DPPH) radical [28]. Briefly, $0.25 \mathrm{ml}$ of $0.15 \mathrm{mM}$ DPPH solution was mixed with $50 \mu \mathrm{l}$ of $\mathrm{OA}$ extract solution of varying concentrations $(1,5$, $10,50,100,250,500$, and $1000 \mu \mathrm{g} / \mathrm{ml})$. After a 30 -minute incubation period in a dark condition, an absorbance at $517 \mathrm{~nm}$ was recorded using a Spectronic ${ }^{\mathrm{TM}}$ GENESYS $^{\text {тм }} 20$ spectrophotometer (Thermo Electron Corporation, IL, USA). Corresponding blank was prepared, and L-ascorbic acid was used as standard reference. Extract concentration which provided 50\% inhibition (IC50) was calculated using the graph by plotting inhibition percentage against extract concentration $[28,29]$.

2.4.2. Ferric Reducing Antioxidant Power (FRAP) Assay. The antioxidant potential to change ferric tripyridyltriazine $\left(\mathrm{Fe}^{3+}-\mathrm{TPTZ}\right)$ complex to ferrous tripyridyltriazine $\left(\mathrm{Fe}^{2+}\right.$-TPTZ) of OA extract was measured by using FRAP assay. FRAP reagent was freshly prepared by mixing $25 \mathrm{ml}$ of $300 \mathrm{mM}$ acetate buffer (Sigma-Aldrich, USA), $\mathrm{pH} 3.6$, and $2.5 \mathrm{ml}$ of $10 \mathrm{mM}$ TPTZ (Sigma-Aldrich, USA) solution in $2.5 \mathrm{ml}$ of $20 \mathrm{mM}$ ferric chloride solution $\left(\mathrm{FeCl}_{3}\right)$ (Sigma-Aldrich, USA) together. Then, $190 \mu \mathrm{l}$ of the FRAP reagent and $100 \mu \mathrm{l}$ of distilled water were mixed with $10 \mu \mathrm{l}$ of $\mathrm{OA}$ extract at various concentrations ranging from 1 to $1000 \mu \mathrm{g} / \mathrm{ml}$. The mixture was incubated at $37^{\circ} \mathrm{C}$ for 10 minutes. After the incubation, an absorbance was recorded at $593 \mathrm{~nm}$ [30]. Ascorbic acid was used as the positive control, and results were expressed as the EC50 value. 
2.5. Measurement of Acetylcholinesterase Inhibitory (AChEI) Activity. AChE suppression activity of OA extract was determined by a colorimetric method according to the method of Ellman et al. [31]. This method is based on the determination of a yellow color of $5,5^{\prime}$-dithiobis (2-nitrobenzoic acid) produced by the hydrolysis of acetylcholine by acetylcholinesterase (AChE). In brief, various concentrations of OA extract at the volume of $25 \mu \mathrm{l}$ each were added to the reaction mixture containing $50 \mu \mathrm{l}$ of Tris- $\mathrm{HCl}$ (50 mM, pH 8.0) (Sigma-Aldrich, USA), $75 \mu \mathrm{l}$ of $3 \mathrm{mM} \mathrm{5,5}$ -dithio-bis-2-nitrobenzoic acid (DTNB) (Sigma-Aldrich, USA), $25 \mu$ l of $15 \mathrm{mM}$ thiocholine iodide (ATCI) (Sigma-Aldrich, USA), and $25 \mu \mathrm{l}$ of AChE $(0.22 \mathrm{U} / \mathrm{ml})$ (Sigma-Aldrich, USA). After mixing, the reaction mixture was incubated at room temperature for 5 minutes, the absorbance at $412 \mathrm{~nm}$ was recorded with a microplate reader (iMark ${ }^{\mathrm{TM}}$ Microplate Absorbance Reader). Percentage of inhibition was calculated by comparing the rate of enzymatic hydrolysis of ATCI for the samples to that of the blank (50\% aqueous methanol in buffer). Donepezil (1-32 mM) (ARICEPT ${ }^{\circledR}$, USA) was used as a reference standard. The AChE inhibition activity of each sample was expressed in terms of EC50. Every sample was assessed in triplicate.

2.6. Determination of Cyclooxygenase-2 (COX-2) Activity. The activity of cyclooxygenase-2 (COX-2), an enzyme playing an important role in inflammatory event, was assessed. Briefly, the reaction mixture containing $150 \mu \mathrm{l}$ of $100 \mathrm{mM}$ Tris- $\mathrm{HCl}$ buffer, $10 \mu \mathrm{l} 0.5 \mu \mathrm{M}$ of heme, $10 \mu \mathrm{l}$ of $50 \mathrm{nM}$ COX-2, and $10 \mu \mathrm{l}$ of OA extract was mixed in 96-well microliter plates. The reaction was initiated with $20 \mu \mathrm{l}$ of $100 \mu \mathrm{M}$ arachidonic acid and $20 \mu \mathrm{l}$ of $10 \mu \mathrm{M}$ of TMPD $\left(\mathrm{N}, \mathrm{N}, \mathrm{N}^{\prime}, \mathrm{N}^{\prime}\right.$ -tetramethyl-p-phenylenediamine) (Cayman Chemical, USA). Then, the plate was incubated at room temperature for 5 minutes. The absorbance at $590 \mathrm{~nm}$ was measured at the end of the incubation period by using a microplate reader. Indomethacin was used as a standard compound. The percentage of COX-2 inhibition was calculated, and results were expressed as the EC50 value [32].

2.7. Finger Print Chromatogram Assessment. The phenolic profiles of OA extract consisting of cyanidin-3-glucoside (Sigma-Aldrich, USA), gallic acid (Sigma-Aldrich, USA), and quercetin-3-O-rutinoside (Sigma-Aldrich, USA) were determined by high-performance liquid chromatography (HPLC). Chromatography was performed by using a Waters ${ }^{\circledR}$ system equipped with a Waters ${ }^{\circledR} 2998$ photodiode array detector. Chromatographic separation was performed using Purospher ${ }^{\circledR}$ STAR, C-18 encapped $(5 \mu \mathrm{m})$, LiChroCART $^{\circledR}$ 250-4.6, and HPLC-Cartridge, Sorbet Lot no. HX255346 (Merck, Germany). The mobile phase (HPLC grade) consisted of $100 \%$ methanol (solvent A) (Fisher Scientific, USA) and $2.5 \%$ acetic acid (solvent B) (Fisher Scientific, USA) in deionized (DI) water was used to induce gradient elution. The gradient elution was carried out at a flow rate of $1.0 \mathrm{ml} / \mathrm{min}$ with the following gradient: $0-17 \mathrm{~min}, 70 \% \mathrm{~A}$; $18-20 \mathrm{~min}, 100 \% \mathrm{~A}$; and $20.5-25 \mathrm{~min}, 10 \% \mathrm{~A}$. The sample was filtered $(0.45 \mu \mathrm{m}$, Millipore), and a direct injection of the tested sample at the volume of $20 \mu \mathrm{l}$ on the column was performed. The chromatograms were recorded at $280 \mathrm{~nm}$ using the UV detector, and data analysis was performed using Empower ${ }^{\mathrm{TM}} 3$.

2.8. Experimental Protocol. Adult male Wistar rats weighing 180-220 grams at the ages between 10 and 14 weeks were obtained from National Laboratory Animal Center, Salaya, Nakhon Pathom, Thailand. The animals were housed in a group of 6 per cage in the standard metal cages at $22 \pm 2^{\circ} \mathrm{C}$ on a $12: 12 \mathrm{~h}$ light: dark cycle and ad libitum access to food and water. All experimental protocols used in this study had been approved by the Institutional Animal Care and Use Committee, Khon Kaen University, Khon Kaen, Thailand (AEKKU 30/2558). After 1 week of acclimatization, rats were divided into seven groups $(n=6)$ as follows:

(1) Group I (naïve intact): rats in this group received a normal diet (4.5\% fat, $42 \%$ carbohydrate, and $24 \%$ protein) and received no treatment

(2) Group II (HCHF+sham operation+vehicle): all rats in this group received a $\mathrm{HCHF}$ diet and subjected to sham operation and vehicle treatment

(3) Group III (HCHF+MCAO+vehicle): animals in this group were $\mathrm{HCHF}$ diet-treated rats which were subjected to reperfusion after the occlusion of right middle cerebral artery (Rt. MCAO) and treated with vehicle

(4) Group IV (HCHF+MCAO+vitamin C): all animals were $\mathrm{HCHF}$ diet-treated rats which were subjected to reperfusion after the occlusion of right middle cerebral artery (Rt. MCAO) and treated with vitamin $\mathrm{C}$ at dose of $250 \mathrm{mg} / \mathrm{kg} \mathrm{BW}$

(5) Groups V-VII ( $\mathrm{HCHF}+\mathrm{MCAO}+\mathrm{OA})(\mathrm{OA} 1, \mathrm{OA} 2$, and $\mathrm{OA} 3$ ): all rats in these groups were $\mathrm{HCHF}$ diet-treated rats which were exposed to reperfusion injury after the occlusion of right middle cerebral artery (Rt. MCAO) and treated with OA extract at various doses ranging from $0.5,5$, to $50 \mathrm{mg} / \mathrm{kg} \mathrm{BW}$

Rats in group II-group VII were fed a high-carbohydrate high-fat diet (HCHF; 35.83\% fat, $35.54 \%$ carbohydrate, and $28.63 \%$ protein) in order to induce metabolic syndrome. After 16 weeks of the feeding period, rats which showed the percentage change of body weight more than 40 percent, fasting plasma glucose more than $100 \mathrm{mg} / \mathrm{dl}$, systolic blood pressure more than 130 or diastolic blood pressure more than $85 \mathrm{mmHg}$, and the atherosclerosis index (total serum cholesterol/total serum HDL-C) higher than the control group were selected for inducing reperfusion injury after the occlusion of Rt. MCAO. Then, the animals were orally given the assigned substances once daily for 21 days. Spatial memory was assessed by using the Morris water maze test every 7 days throughout a 21-day study period. At the end of the study period, neuron density, the oxidative stress status, AChE, density of glial fibrillary acidic protein- (GFAP-) positive cell, and the expressions of proinflammatory cytokines 


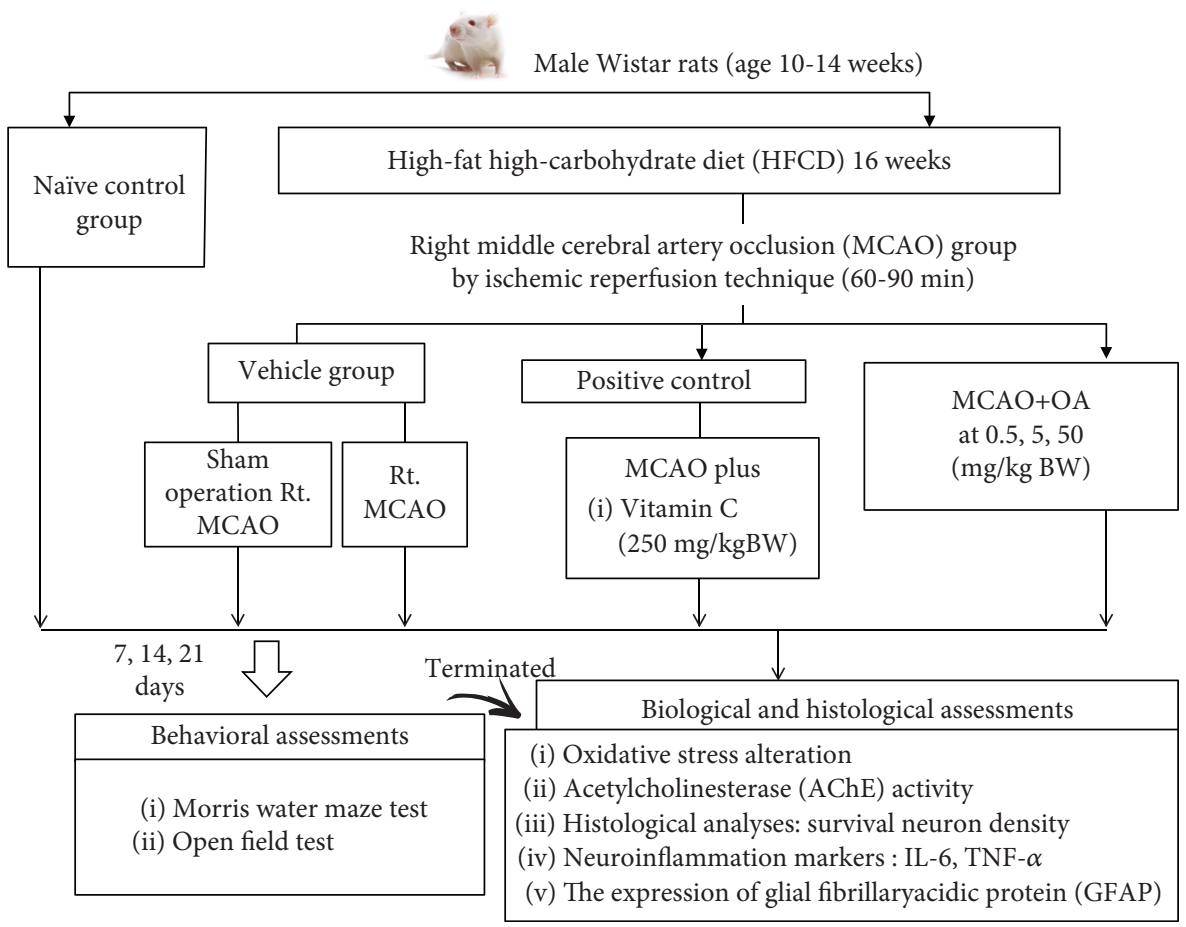

(a)

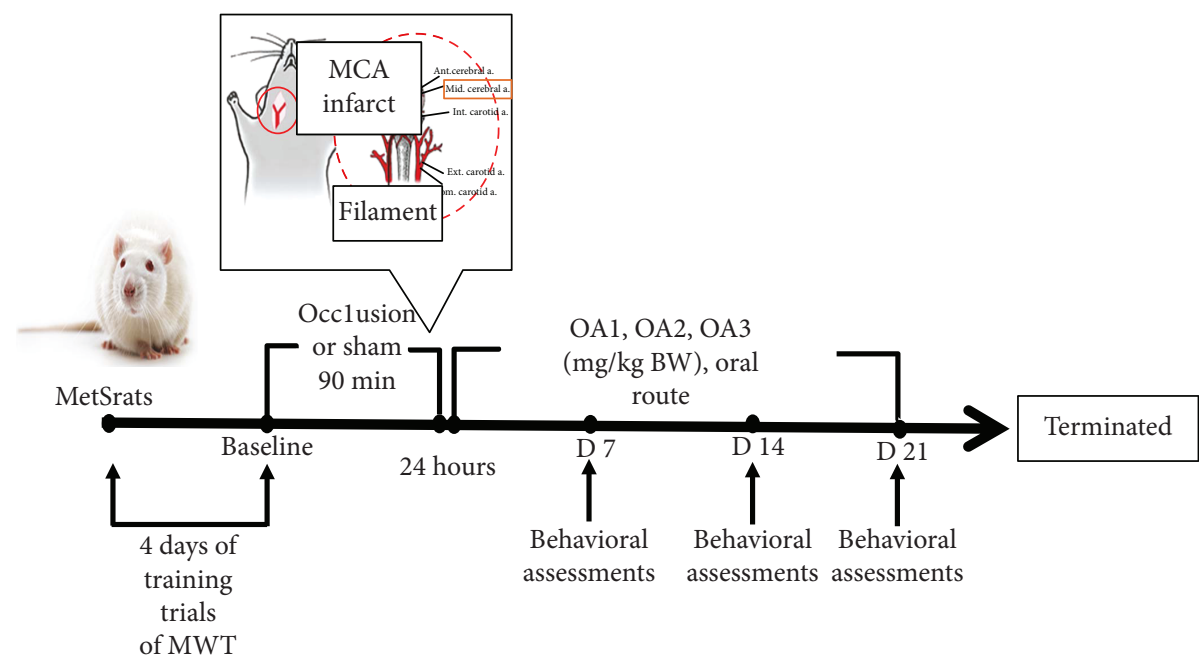

(b)

FIGURE 1: Schematic diagram showing all experimental procedures. (a) Experimental protocol of OA extract treatment and the determination of various parameters. (b) Right MCAO induction and schedule for OA extract treatment. IL-6: interleukin-6; TNF- $\alpha$ : tumor necrosis factor- $\alpha$; HCHF: high- high-fat diet; MCAO: right middle cerebral artery occlusion; OA1, OA2, and OA3: the combined extract of $O$. sativa and A. graveolens at doses of $0.5,5$, and $50 \mathrm{mg} / \mathrm{kg} \mathrm{BW}$, respectively.

(TNF- $\alpha$, IL-6) in the hippocampus were determined. The schematic diagram showing the experimental protocol was shown in Figure 1.

2.9. Focal Cerebral Ischemia/Reperfusion Induction. The rats were anesthetized with an intraperitoneal injection of pentobarbital sodium (50 mg/kg BW; Tianjin Kemiou Chemical Reagent Co. Ltd., Tianjin, China). Then, the monofilament was inserted via the right common carotid artery, and the right external carotid artery (ECA) was exposed through a ventral midline neck incision and was ligated proximally. A silicone-coated nylon monofilament (4-0) suture (USS DG; Tyco Healthcare Group LP, CT, USA), with its tip rounded by heating near a flame, was inserted $17-18 \mathrm{~mm}$ into the right internal carotid artery (ICA) from distal to the carotid bifurcation, to occlude the origin of the MCA. The suture was fixed, and the incision was closed. Following $90 \mathrm{~min}$ of ischemia, the nylon suture was withdrawn to allow reperfusion. The sham-operated rats underwent identical surgery, but the nylon suture was not inserted. After 1 week of operation, 
rats in groups V-VII were subjected to the assigned treatments once daily for a period of 21 days.

2.10. Spatial Memory Assessment. Spatial memory was assessed by using the Morris water maze test. The water maze apparatus is a circular pool at the diameter of $147 \mathrm{~cm}$ and filled with tap water to the depth of $40 \mathrm{~cm}$. The surface was covered with nontoxic powder. The pool was divided into 4 equal quadrants, and the removable escape platform was placed in the center on one quadrant below the water level. The location of the platform was invisible, and it remained there throughout the training. Each animal was trained to memorize the location of the platform by forming the association information between its location and the location of platform by using external cues. After 4 training sessions, animal was placed in the water in the starting quadrant and allowed to swim until the animal found and climbed onto the platform. The time which the animal spent to reach the hidden platform was recorded as escape latency. The retention time was determined $24 \mathrm{~h}$ later by exposing the animal to subject to the same situation as mentioned earlier except that the immersed platform was removed and the time which the animal spent for swimming in the quadrant previously located platform was regarded as retention time [25].

2.11. Locomotor Assessment. The effect of the developed product on locomotor activity was assessed by using an open field test, the most frequently used method. A $90 \mathrm{~cm}$ square plexiglass chamber with a $70 \mathrm{~cm}$ height was used for behavioral evaluation. The tests were performed in a room lit by a $60 \mathrm{~W}$ light bulb $1.75 \mathrm{~m}$ above the center of the open field. Each animal was placed into the center of the open field chamber and allowed to explore the apparatus for 5 minutes. Every time both hind paws entered one of these squares, a crossing was recorded. In addition to the number of crossing, the number of center square entries was also recorded. The number of licking, rearing, and grooming was also monitored by using a video tracking system [33].

\subsection{Histological Study}

2.12.1. Nissl Staining. For histopathological analysis, the brains were perfused transcardially with fixative solution containing 4\% paraformaldehyde (Sigma-Aldrich, USA) in $0.1 \mathrm{M}$ phosphate buffer $\mathrm{pH} 7.4$ overnight at $4^{\circ} \mathrm{C}$. Then, they were infiltrated with $30 \%$ sucrose (Merck, Germany) solution for $72 \mathrm{~h}$ at $4^{\circ} \mathrm{C}$. Serial sections of tissues were cut frozen on a cryostat (Thermo Scientific ${ }^{\mathrm{TM}}$ HM 525 Cryostat) at $20 \mu \mathrm{m}$ thick. All sections were picked up on slides coated with $0.3 \%$ aqueous solution of gelatin containing $0.05 \%$ aluminium potassium sulfate (Sigma-Aldrich, USA). The triplicate coronal sections of brains were immersed in $0.2 \%$ cresyl violet (Sigma-Aldrich, USA) for 8 minutes, rinsed with double distilled water, and dehydrated through graded alcohols (70, 95, and 100\% 2x) (RCI Labscan, Thailand). The sections were cleared with xylene for 5 minutes (2 times) and mounted using DPX mountant (Merck, Germany). The evaluation of neuron density in the hippocampus was performed under an Olympus light microscope model BH-2 (Japan) at 40x magnification. Counts were performed in three adjacent fields, and the mean number was calculated and expressed as density of neurons per $255 \mu \mathrm{m}^{2}$.

2.12.2. Immunohistochemistry. Brain sections containing the hippocampus were prepared as mentioned in Section 2.12.1. All sections were picked up on slides coated with $0.3 \%$ aqueous solution of gelatin containing $0.05 \%$ aluminium potassium sulfate (Sigma-Aldrich, USA). The sections were heated using a microwave oven in $0.01 \mathrm{M}$ sodium citrate buffer ( $\mathrm{pH}$ 6.0) for 10 minutes and cooled at room temperature. The sections were subjected to a 5-minute washing step with phosphate-buffered saline (PBS) for 3 times and incubated in $0.3 \%$ hydrogen peroxide at room temperature for 20 minutes. At the end of the incubation period, the sections were subjected to a 5-minute washing with PBS for 3 times. Then, they were incubated in the mixture containing $0.3 \%$ Triton X-100 (Fluka Chemika, Buchs, Switzerland), 1\% $(w / v)$ bovine serum albumin (BSA), and 10\% normal goat serum at room temperature for 20 minutes. Following this process, the sections were washed with PBS for three times ( 5 minutes each) and incubated with primary anti-GFAP (Abcam, Cambridge, MA, USA) at a dilution of $1: 500$ (diluted in the solution containing $0.01 \mathrm{M}$ PBS with $1 \%$ Triton X-100 and $10 \%$ normal serum) at $4^{\circ} \mathrm{C}$ overnight. Following this step, the sections were washed and incubated with REAL $^{\text {TM }}$ EnVision $^{\text {TM }}$ Detection System, Peroxidase/DAB+ rabbit/mouse (Dako, Glostrup, Denmark) at room temperature for 30 minutes. At the end of the incubation period, the sections were rinsed with PBS and incubated with $3,3^{\prime}$ -diaminobenzidine tetrahydrochloride (DAB) (Sigma-Aldrich, USA) for 5 minutes. Positive staining was recognized as a brown color. Negative control sections were subjected to the same procedures except the exposure to primary antibody. The sections were mounted on gelatin-coated slides, counterstained with cresyl violet, dehydrated with graded alcohols, cleared with xylene, and mounted with DPX mountant. The numbers of positive cells in an area of $255 \mu \mathrm{m}^{2}$ were counted. The data were shown as mean and standard error. Cell counts were carried out by a technician who is blind to the experimental design. All measurements were repeated for three times, and the mean value was used.

2.13. Brain Homogenate Preparation. Hippocampi were isolated, weighed, and homogenized with a buffer consisting of 50 volume of $0.1 \mathrm{M}$ phosphate-buffered saline. Then, the brain homogenates were centrifuged at $3000 \mathrm{~g}$ for $15 \mathrm{~min}$ at $4^{\circ} \mathrm{C}$. Supernatant of tissue homogenates was collected and used for the determinations of acetylcholinesterase (AChE) and oxidative stress markers including malondialdehyde (MDA) and the activities of main scavenger enzymes such as catalase (CAT), superoxide dismutase (SOD), and glutathione peroxidase (GSH-Px). The protein concentration in brain homogenate was also determined by using a Thermo Scientific NanoDrop 2000c spectrophotometer (Thermo Fisher Scientific, Wilmington, Delaware, USA).

\subsection{Biochemical Assessments}

2.14.1. Oxidative Stress Marker Assessment. The level of malondialdehyde (MDA), a lipid peroxidation product, in 
the brain was determined by determining the accumulation of thiobarbituric acid reactive substances (TBARSs) according to the method of Ohkawa et al. and Harishekar and Kiran $[34,35]$. In brief, $50 \mu \mathrm{l}$ of sample was mixed with the solution containing $50 \mu \mathrm{l}$ of $8.1 \%$ sodium dodecyl sulphate (SDS) (Sigma-Aldrich, USA), $375 \mu \mathrm{l}$ of $0.8 \%$ of thiobarbituric acid (TBA) (Sigma-Aldrich, USA), $375 \mu$ l of $20 \%$ acetic acid (Sigma-Aldrich, USA), and $150 \mu$ l of distilled water (DW). Then, the mixture was boiled in a water bath at $95^{\circ} \mathrm{C}$ for 1 hour and cooled immediately under tap water. Then, $250 \mu \mathrm{l}$ of DW and $1250 \mu \mathrm{l}$ of the solution containing n-butanol and pyridine $(15: 1 v / v)$ (Merck, Germany) were added and mixed together and centrifuged at $4000 \mathrm{rpm}$ for 10 minutes. The upper layer was separated, and the absorbance at $532 \mathrm{~nm}$ was measured. 1,3,3-Tetramethoxy propane (0-15 $\mu \mathrm{M})$ (Sigma-Aldrich, USA) was used as the standard, and the level of MDA was expressed as ng/mg protein.

SOD activity was monitored based on the inhibition of nitroblue tetrazolium (NBT) reduction [36]. In brief, $20 \mu \mathrm{l}$ of sample was mixed with the reaction mixture containing $57 \mathrm{mM}$ phosphate buffer solution $\left(\mathrm{KH}_{2} \mathrm{PO}_{4}\right)$ (Sigma-Aldrich, USA), $0.1 \mathrm{mM}$ EDTA (Sigma-Aldrich, USA), $10 \mathrm{mM}$ cytochrome C solution (Sigma-Aldrich, USA), $50 \mu \mathrm{M}$ of xanthine solution, and $20 \mu \mathrm{l}$ of xanthine oxidase solution $(0.90 \mathrm{mU} / \mathrm{ml})$ at $25^{\circ} \mathrm{C}$. The absorbance at $415 \mathrm{~nm}$ was measured. SOD enzyme (Sigma-Aldrich, USA) activities at the concentrations of $0-25$ units/ml were used as the standard, and the results were expressed as units/mg protein.

Catalase activity measurement was carried out spectrophotometrically by measuring the decrease in absorbance of $\mathrm{H}_{2} \mathrm{O}_{2}$ [37]. In brief, $50 \mu \mathrm{l}$ of $30 \mathrm{mM}$ hydrogen peroxide (in $50 \mathrm{mM}$ phosphate buffer, $\mathrm{pH} 7.0$ ) (BDH Chemicals Ltd., UK), $25 \mu \mathrm{l}$ of $\mathrm{H}_{2} \mathrm{SO}_{4}$ (Sigma-Aldrich, USA), $150 \mu \mathrm{l}$ of $5 \mathrm{mM} \mathrm{KM}_{\mathrm{n}} \mathrm{O}_{4}$ (Sigma-Aldrich, USA), and $10 \mu \mathrm{l}$ of tissue homogenate were mixed thoroughly, and changes in an absorbance of the reaction solution at $490 \mathrm{~nm}$ were determined. CAT enzyme (Sigma-Aldrich, USA) at the concentration range of $0-100$ units/ml was used as the standard, and the result was expressed as units/mg protein.

In order to determine the activity of GSH-Px, the mixture containing $10 \mu \mathrm{l}$ of $1 \mathrm{mM}$ dithiothreitol (DTT) (Sigma-Aldrich, USA) in $6.67 \mathrm{mM}$ potassium phosphate buffer ( $\mathrm{pH} 7$ ), $100 \mu \mathrm{l}$ of $1 \mathrm{mM}$ sodium azide (Sigma-Aldrich, USA) in $6.67 \mathrm{mM}$ potassium phosphate buffer $(\mathrm{pH} 7), 10 \mu \mathrm{l}$ of $50 \mathrm{mM}$ glutathione (Sigma-Aldrich, USA) solution, $100 \mu \mathrm{l}$ of $30 \%$ hydrogen peroxide (BDH Chemicals Ltd., UK), and $20 \mu \mathrm{l}$ of sample solution was mixed and incubated at room temperature for 5 minutes. Then, $10 \mu \mathrm{l}$ of $10 \mathrm{mM}$ DTNB (5,5-dithiobis-2-nitrobenzoic acid) (Sigma-Aldrich, USA) was added, and the optical density at $412 \mathrm{~nm}$ was recorded at $25^{\circ} \mathrm{C}$ over a period of $5 \mathrm{~min}$ [38]. The standard calibration curve was prepared by using GSH-Px enzyme (Sigma-Aldrich, USA) at the concentration range of $0-5$ units $/ \mathrm{ml}$. GSH-Px activity was expressed as units/mg protein.

2.14.2. In Vivo Assessment of AChE. The activity of rat brain AChE was determined by the method of Ellman with a slight modification [31]. In brief, a mixture containing a $20 \mu \mathrm{l}$ of sample solution, $200 \mu \mathrm{l}$ of $0.1 \mathrm{mM}$ sodium phosphate buffer
(pH 8.0) (Sigma-Aldrich, USA), and $10 \mu \mathrm{l}$ of $0.2 \mathrm{M}$ DTNB (5,5'-dithio-bis-(2-nitrobenzoic acid)) (Sigma-Aldrich, USA) was mixed and incubated at room temperature for 5 minutes. Then, $10 \mu \mathrm{l}$ of $15 \mathrm{mM}$ acetylcholine thiochloride (ACTI) (Sigma-Aldrich, USA) was added and incubated for 3 minutes. The change in absorbance of light was measured at $412 \mathrm{~nm}$ for 3 minutes at regular intervals of 30 seconds using a microplate reader (iMark ${ }^{\mathrm{TM}}$ Microplate Absorbance Reader). The activity of AChE was calculated according to the equation below and expressed as $\mathrm{nmol} / \mathrm{min} \cdot \mathrm{mg}$ protein.

$$
\operatorname{AChE} \text { activity }=\left(\frac{\Delta A}{\left(1.36 \times 10^{4}\right)}\right) \times\left(\frac{1}{(20 / 230)}\right) C,
$$

where $\Delta A=$ the difference of absorbance/minute and $C=$ protein concentration of brain homogenate.

2.15. Western Blotting Analysis. The hippocampus was homogenized in the mammalian protein extraction reagent (M-PER; Pierce Protein Biology Product, Rockford, IL, USA), with protease inhibitor cocktail (1:10) (Sigma-Aldrich, USA). Then, the samples were centrifuged at $12,000 \mathrm{~g}$ for 10 minutes at $4^{\circ} \mathrm{C}$, and the supernatant was collected and stored on ice for protein determination by using a Thermo Scientific NanoDrop 2000c spectrophotometer (Thermo Fisher Scientific, Wilmington, Delaware, USA). For each animal, $80 \mu \mathrm{g}$ of hippocampal lysate was adjusted to appropriate concentration by using Tris-Glycine SDS-PAGE loading buffer (Bio-Rad, USA) and heated at $95^{\circ} \mathrm{C}$ for 10 minutes. In addition, $20 \mu \mathrm{l}$ of tissue sample protein was loaded onto SDS-polyacrylamide gel and separated by sodium dodecyl sulfate-polyacrylamide gel electrophoresis (SDS-PAGE). Biotinylated broad-range molecular weight markers (Bio-Rad) were loaded onto the gels as well. After electrophoretic separation, proteins were transferred to a nitrocellulose membrane by electroblotting, washed with $0.05 \%$ TBS-T, and incubated overnight at $4^{\circ} \mathrm{C}$ in blocking buffer (PBS containing 1\% Tween-20 (T-PBS) and 6.5\% nonfat dry milk). Membranes were then incubated overnight at $4^{\circ} \mathrm{C}$ with polyclonal rabbit TNF- $\alpha$ (\#3707) and IL-6 (\#12912) primary antibodies (Cell Signaling Technology, USA; dilution $1: 1000$ ), rinsed with T-PBS for 30 minutes, and incubated with anti-rabbit IgG, HRP-linked antibody (Cell Signaling Technology, USA; dilution 1:2000) at room temperature for 1 hour. The bands were visualized and quantitated by using the ECL detection systems (GE Healthcare) and LAS-4000 luminescent image analyzer (GE Healthcare). Band intensities were measured for statistical analysis using the ImageQuant TL v.7.0 image analysis software (GE Healthcare). The expression was normalized using $\beta$-actin (Cell Signaling Technology, USA; dilution $1: 2000)$. Data were presented as a relative density to the control normal group.

2.16. Statistical Analysis. All data are expressed as mean \pm standard error of mean (SEM). Statistical significance was evaluated by using one-way analysis of variance (ANOVA), followed by the post hoc (Tukey) test. The statistical significance was regarded at $P$ values $<0.05$. 
TABLE 1: Characterization of OA extract including phenolic compositions and biological activities.

\begin{tabular}{|c|c|c|c|c|c|}
\hline Parameters & Units & O. sativa & A. graveolens & OA extract & Standard reference \\
\hline Total phenolic & $\mu \mathrm{g}$ GAE/mg extract & $824.62 \pm 90.98$ & $941.54 \pm 41.63$ & $1724.10 \pm 159.73^{\text {aaa,bb }}$ & - \\
\hline Total flavonoids & $\mu$ g quercetin/mg extract & $47.40 \pm 2.98$ & $23.81 \pm 0.32$ & $62.18 \pm 1.03^{\mathrm{aaa}, \mathrm{bbb}}$ & - \\
\hline \multicolumn{6}{|c|}{ Antioxidant activities } \\
\hline DPPH & $\mathrm{EC} 50(\mathrm{mg} / \mathrm{ml})$ & $0.123 \pm 0.01$ & $0.065 \pm 0.02$ & $0.014 \pm 0.003^{\mathrm{aa}}$ & $0.008 \pm 0.002$, ascorbic acid \\
\hline FRAP & EC50 (mg/ml) & $2.56 \pm 0.37$ & $2.99 \pm 0.055$ & $1.19 \pm 0.24^{\mathrm{a}, \mathrm{b}}$ & $2.56 \pm 0.14$, ascorbic acid \\
\hline \multicolumn{6}{|l|}{ Neuronal marker } \\
\hline AChE inhibition & $\operatorname{EC} 50(\mathrm{mg} / \mathrm{ml})$ & $2.03 \pm 1.08$ & $2.94 \pm 0.62$ & $1.98 \pm 0.15$ & $0.67 \pm 0.001$, donepezil \\
\hline \multicolumn{6}{|c|}{ Inflammatory marker } \\
\hline COX-2 inhibition & EC50 (mg/ml) & $9.37 \pm 1.18$ & $142.44 \pm 15.82$ & $1.73 \pm 0.44^{\mathrm{bbb}}$ & $0.02 \pm 0.001$, indomethacin \\
\hline
\end{tabular}

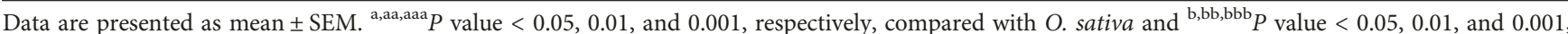
respectively, compared with A. graveolens. OA extract: the combined extract of O. sativa and A. graveolens.

\section{Results}

3.1. Characterization of the Combined Extract of $O$. sativa and $A$. graveolens (OA Extract). The characterization of the combined extract of $O$. sativa and $A$. graveolens or OA extract was shown in Table 1. O. sativa extract and A. graveolens contained the phenolic compounds at the concentrations of $824.62 \pm 90.98$ and $941.54 \pm 41.63 \mu \mathrm{g} \mathrm{GAE} / \mathrm{mg}$ extract while the concentration of this substance in the combined extract of O. sativa and A. graveolens (OA extract) was $1724.10 \pm$ $159.73 \mu \mathrm{g} \mathrm{GAE} / \mathrm{mg}$ extract. In addition, the flavonoid contents in $O$. sativa and $A$. graveolens were $47.40 \pm 2.98$ and $23.81 \pm 0.32 \mu \mathrm{g}$ quercetin/mg extract, respectively. It was found that the concentration of flavonoid content in $\mathrm{OA}$ extract was $62.18 \pm 1.03 \mu \mathrm{g}$ quercetin/mg extract. The contents of phenolic compounds and flavonoids in OA extract were significantly higher than those in $O$. sativa ( $P$ value $<0.001$ all $)$ and $A$. graveolens ( $P$ value $<0.01$ and 0.001$)$. The antioxidant activities were assessed by using DPPH and FRAP assays. The current results showed that EC50 of O. sativa and A. graveolens via DPPH assay were $0.123 \pm 0.01$ and $0.065 \pm 0.02 \mathrm{mg} / \mathrm{ml}$ while EC50 of both substances mentioned earlier via FRAP assay were $2.56 \pm 0.37$ and $2.99 \pm 0.055 \mathrm{mg} / \mathrm{ml}$, respectively. It was found that EC50 of OA extract via DPPH and FRAP assays were $0.014 \pm 0.003$ and $1.19 \pm 0.24 \mathrm{mg} / \mathrm{ml}$, respectively. The antioxidant activity of OA extract assessed via DPPH assay showed the significant higher potent activity than the antioxidant activity of $O$. sativa $(P$ value $<0.01)$ while the antioxidant activity of OA extract assessed via FRAP assay showed the significant higher potent activity than the activity of both $O$. sativa and $A$. graveolens ( $P$ value $<0.05$ all). O. sativa also showed that EC50 of acetylcholinesterase suppression and cyclooxygenase-2 (COX-2) suppression activities were $2.03 \pm 1.08$ and $9.37 \pm 1.18 \mathrm{mg} / \mathrm{ml}$, respectively. EC50 of both mentioned activities of $A$. graveolens were $2.94 \pm 0.62$ and $142.44 \pm 15.82 \mathrm{mg} / \mathrm{ml}$, respectively. The present data showed that EC50 of acetylcholinesterase suppression and cyclooxygenase-2 (COX-2) suppression activities of OA extract were $1.98 \pm 0.15$ and $1.73 \pm 0.44 \mathrm{mg} / \mathrm{ml}$, respectively. It is also clearly shown that COX-2 suppression activity of

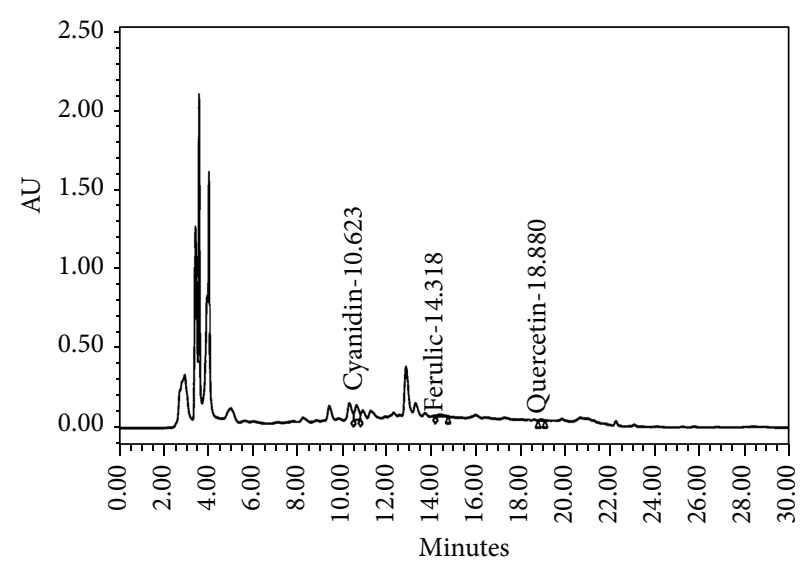

FIgURE 2: The chromatogram finger print of OA extract $(100 \mathrm{mg} / \mathrm{ml})$ using Purospher ${ }^{\circledR}$ STAR, C-18 encapped $(5 \mu \mathrm{m})$, LiChroCART $^{\circledR}$ 250-4.6, and HPLC-Cartridge, Sorbet Lot no. HX255346 (Merck, Germany) with guard column (Merck, Germany).

OA extract was significantly potent than that of $A$. graveolens $(P$ value $<0.001)$.

The fingerprint chromatogram of OA extract was also determined, and data were shown in Figure 2. The contents of cyanidin-3-glucoside, quercetin, and ferulic acid in OA extract were $0.52 \pm 0.003 \mu \mathrm{g}$ Cyn-3-glu/50 mg of extract, $3.00 \pm 0.58 \mu \mathrm{g}$ QE/50 mg of extract, and $1.16 \pm 0.12 \mu \mathrm{g}$ ferulic acid/50 mg of extract, respectively.

3.2. Cognitive Enhancing Effect of OA Extract. Figure 3 showed that no significant changes in escape latency among various groups were observed at 7 and 14 days after MCAO. However, metabolic syndrome rats induced by a HCHF diet which subjected to MCAO and received vehicle significantly increased escape latency $(P$ value $<0.01$, compared to the $\mathrm{HCHF}+$ sham operation+vehicle group). Interestingly, this change was attenuated by vitamin $\mathrm{C}$ and $\mathrm{OA}$ extract at doses of $0.5,5$, and $50 \mathrm{mg} / \mathrm{kg}$ ( $P$ value $<0.05,0.01,0.001$, and 0.01 , respectively, compared to the $\mathrm{HCHF}+\mathrm{MCAO}+$ vehicle group). In addition, MCAO also decreased retention time 


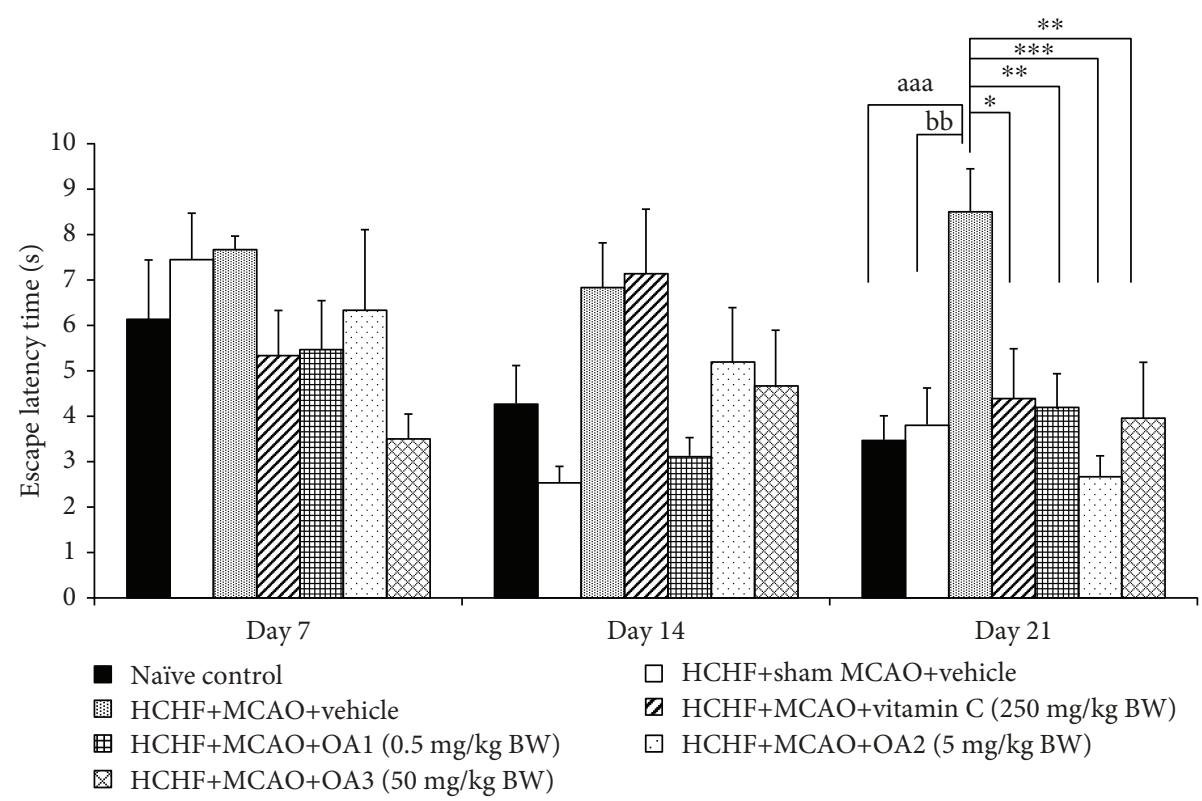

FIGURE 3: Effect of OA extract on escape latency time. Data are presented as mean \pm SEM ( $n=6$ /group). ${ }^{\text {aaa }} P$ value $<0.001$, compared to naïve intact rats; ${ }^{\mathrm{bb}} P$ value $<0.01$, compared to sham operation which received HCHF diet and vehicle; and ${ }^{*, * *, * * *} P$ value $<0.05,0.01$, and 0.001 , respectively, compared to MCAO rats which received HCHF and vehicle. HCHF: high-carbohydrate high-fat diet; MCAO: right middle cerebral artery occlusion; OA1, OA2, and OA3: the combined extract of O. sativa and A. graveolens at doses of 0.5, 5, and 50 mg/kg BW, respectively.

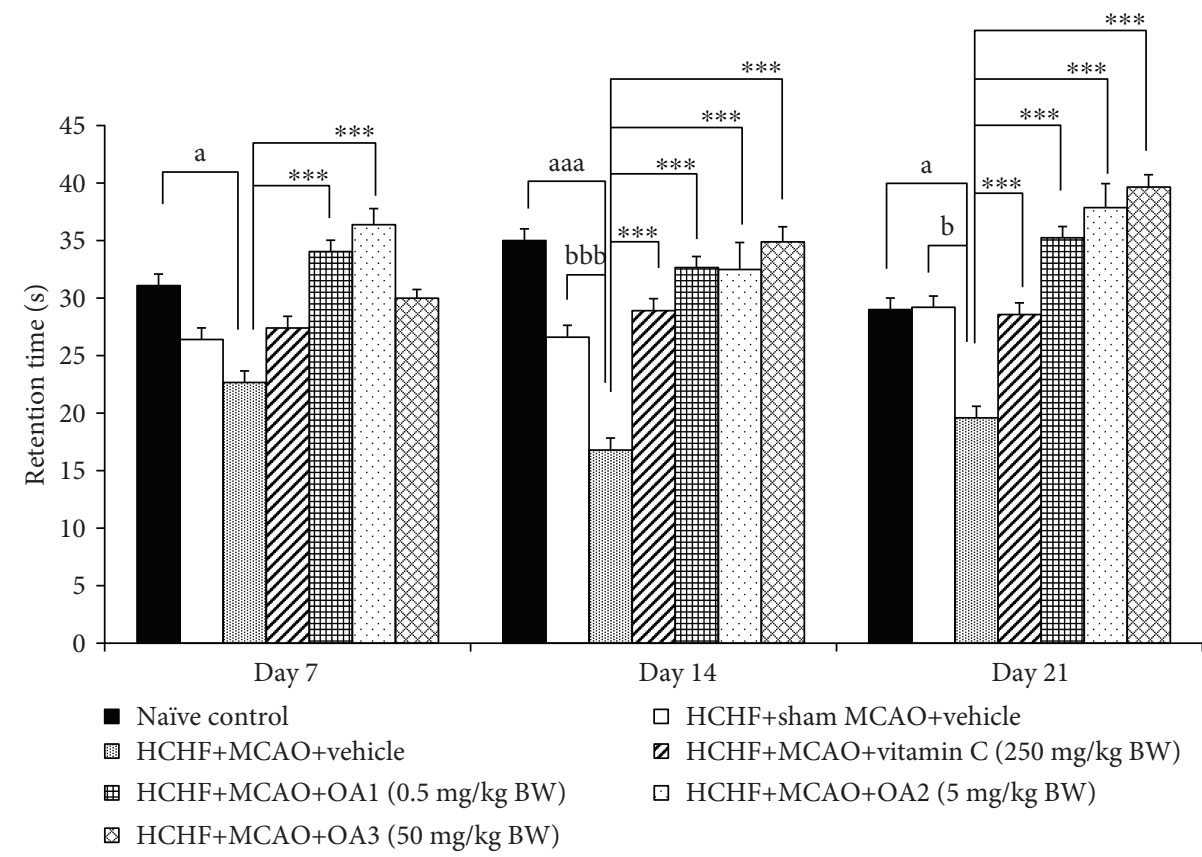

FIGURE 4: Effect of OA extract on retention time. Data are presented as mean \pm SEM ( $n=6$ /group). ${ }^{\text {a,aaa }} P$ value $<0.05$ and 0.001 , respectively, compared to naïve intact rats; ${ }^{\mathrm{b}, \mathrm{bbb}} P$ value $<0.01$ and 0.001 , respectively, compared to sham operation which received HCHF diet and vehicle; and ${ }^{* * *} P$ value $<0.001$, compared to MCAO rats which received HCHF and vehicle. HCHF: high-carbohydrate high-fat diet; MCAO: right middle cerebral artery occlusion; OA1, OA2, and OA3: the combined extract of O. sativa and A. graveolens at doses of 0.5, 5, and 50 mg/kg BW, respectively.

in metabolic rats which received vehicle at 14 and 21 days after MCAO ( $P$ value $<0.001$ and 0.05 , respectively, compared to the $\mathrm{HCHF}+$ sham operation+vehicle group).
These changes were also mitigated both at 14 and 21 days after MCAO ( $P$ value $<0.001$ all, compared to the $\mathrm{HCHF}+\mathrm{MCAO}+$ vehicle group) as shown in Figure 4. To 


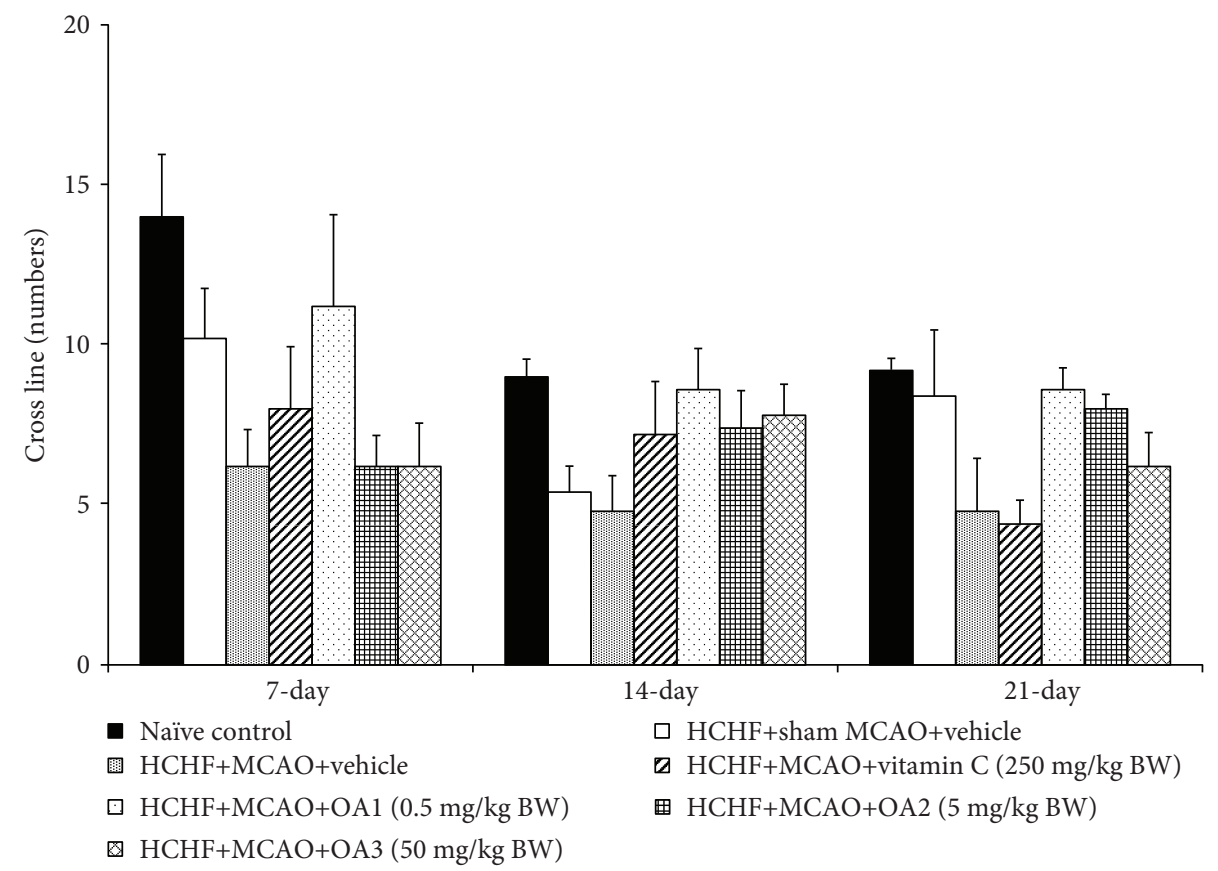

(a)

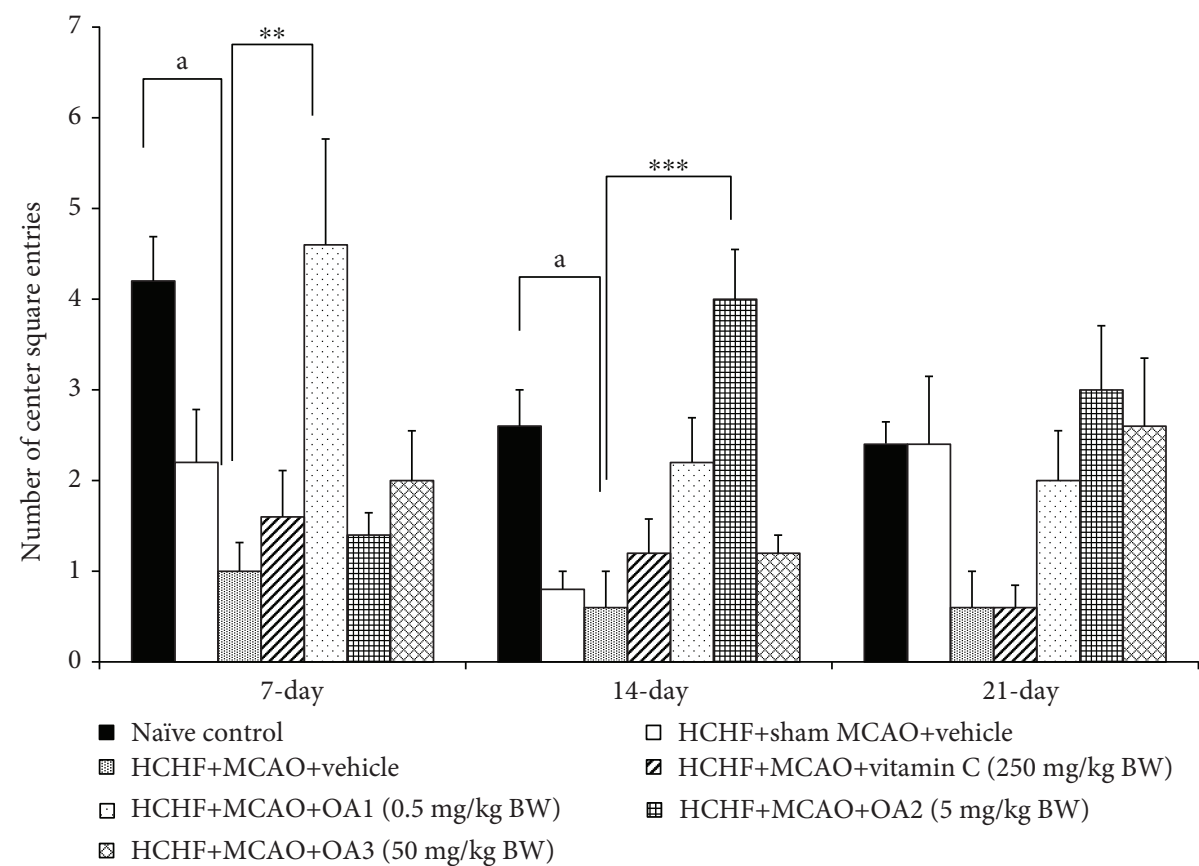

(b)

FIGURE 5: Effect of OA extract on locomotor activities: (a) the number of cross line and (b) the number of center square entries. Data are presented as mean \pm SEM ( $n=6 /$ group). ${ }^{a} P$ value $<0.05$, compared to naïve intact rats and ${ }^{* * * * *} P$ value $<0.01$ and 0.001 , respectively, compared to MCAO rats which received HCHF and vehicle. HCHF: high-carbohydrate high-fat diet; MCAO: right middle cerebral artery occlusion; OA1, OA2, and OA3: the combined extract of $O$. sativa and A. graveolens at doses of $0.5,5$, and $50 \mathrm{mg} / \mathrm{kg} \mathrm{BW,} \mathrm{respectively.}$

assure that the cognitive enhancing effect observed in this study was not the false positive, the effect of OA extract on locomotor activity was also evaluated and results were shown in Figures 5 and 6. Our data showed that obese rats which subjected to MCAO and received vehicle $(\mathrm{HCHF}+\mathrm{MCAO}+$ vehicle) significantly decreased the number of center square entry at days 7 and 14 after MCAO
( $P$ value $<0.05$ all, compared to the naïve control). However, low and medium doses of OA extract could counteract the reduction of this parameter at 7 and 14 days after MCAO, respectively $(P$ value $<0.01$ and 0.001 , respectively, compared to $\mathrm{MCAO}$ rats which received HCHF and vehicle). No other significant changes were observed. 


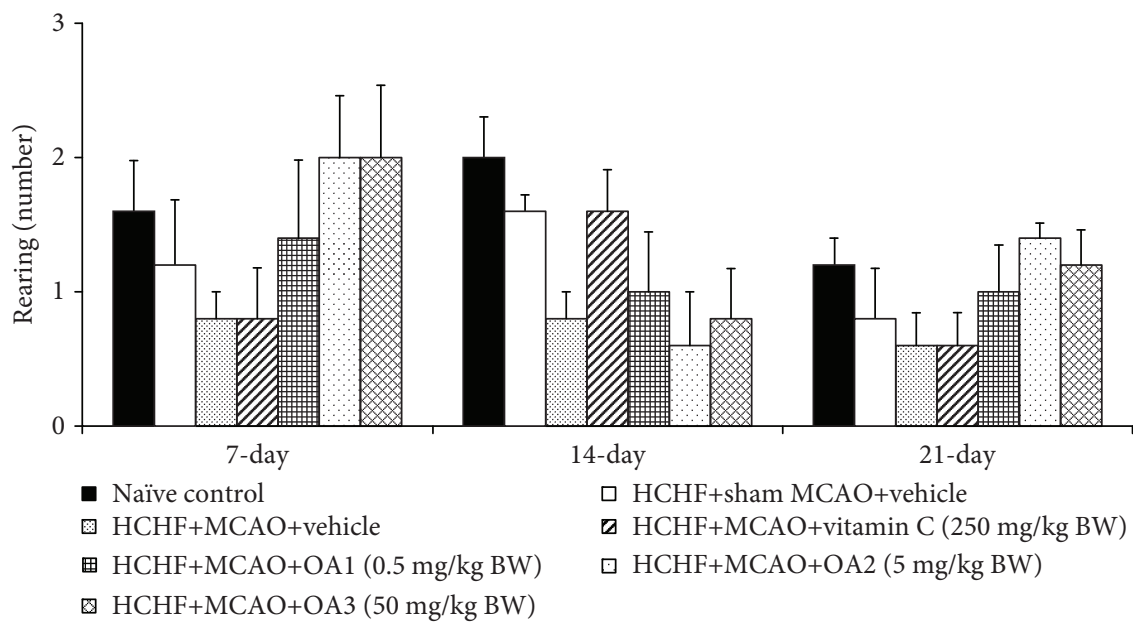

(a)

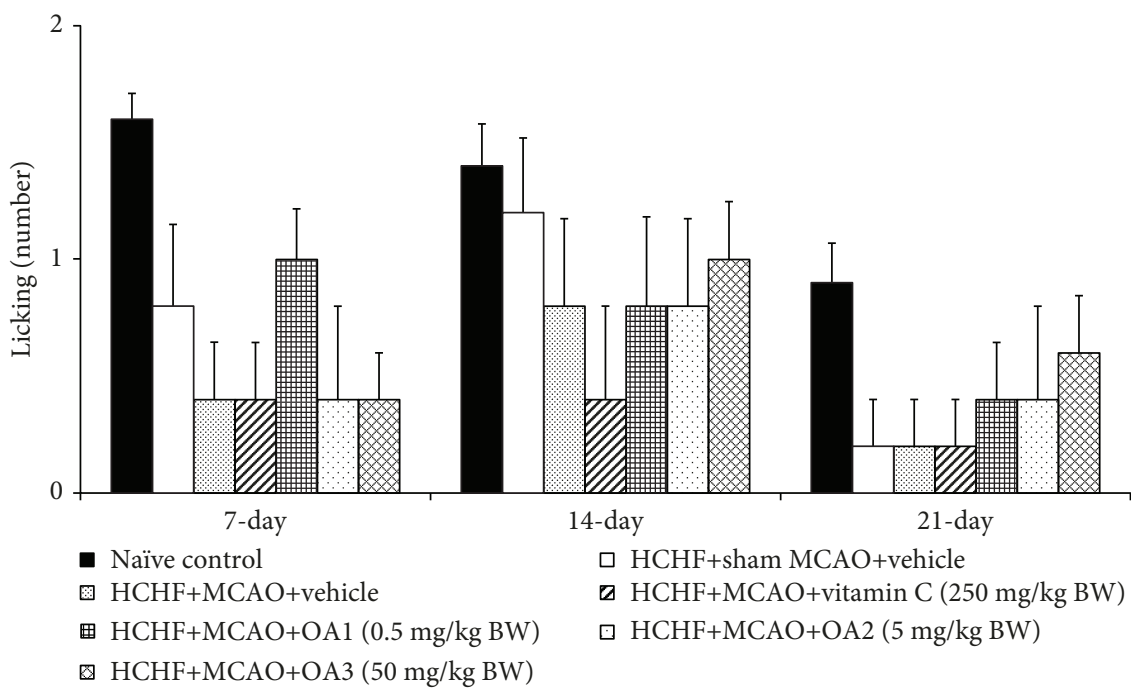

(b)

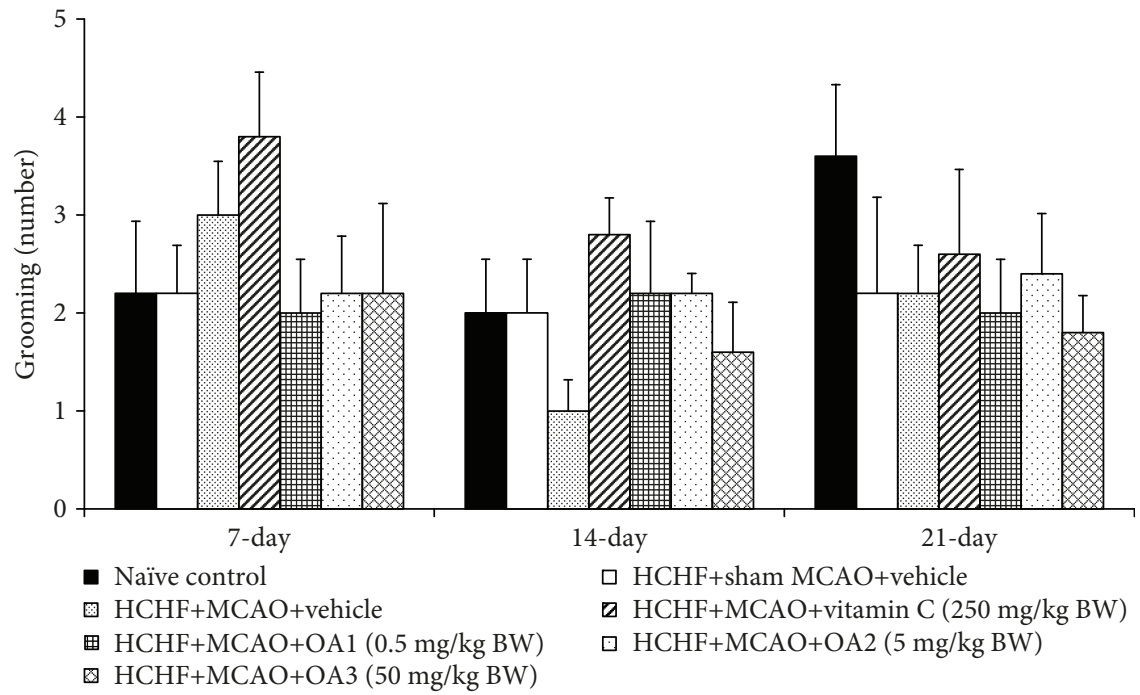

(c)

FIGURE 6: Effect of OA extract on exploratory activities: (a) licking, (b) rearing, and (c) grooming behaviors. Data are presented as mean \pm SEM ( $n=6$ /group). HCHF: high-carbohydrate high-fat diet; MCAO: right middle cerebral artery occlusion; OA1, OA2, and OA3: the combined extract of $O$. sativa and A. graveolens at doses of $0.5,5$, and $50 \mathrm{mg} / \mathrm{kg} \mathrm{BW}$, respectively. 


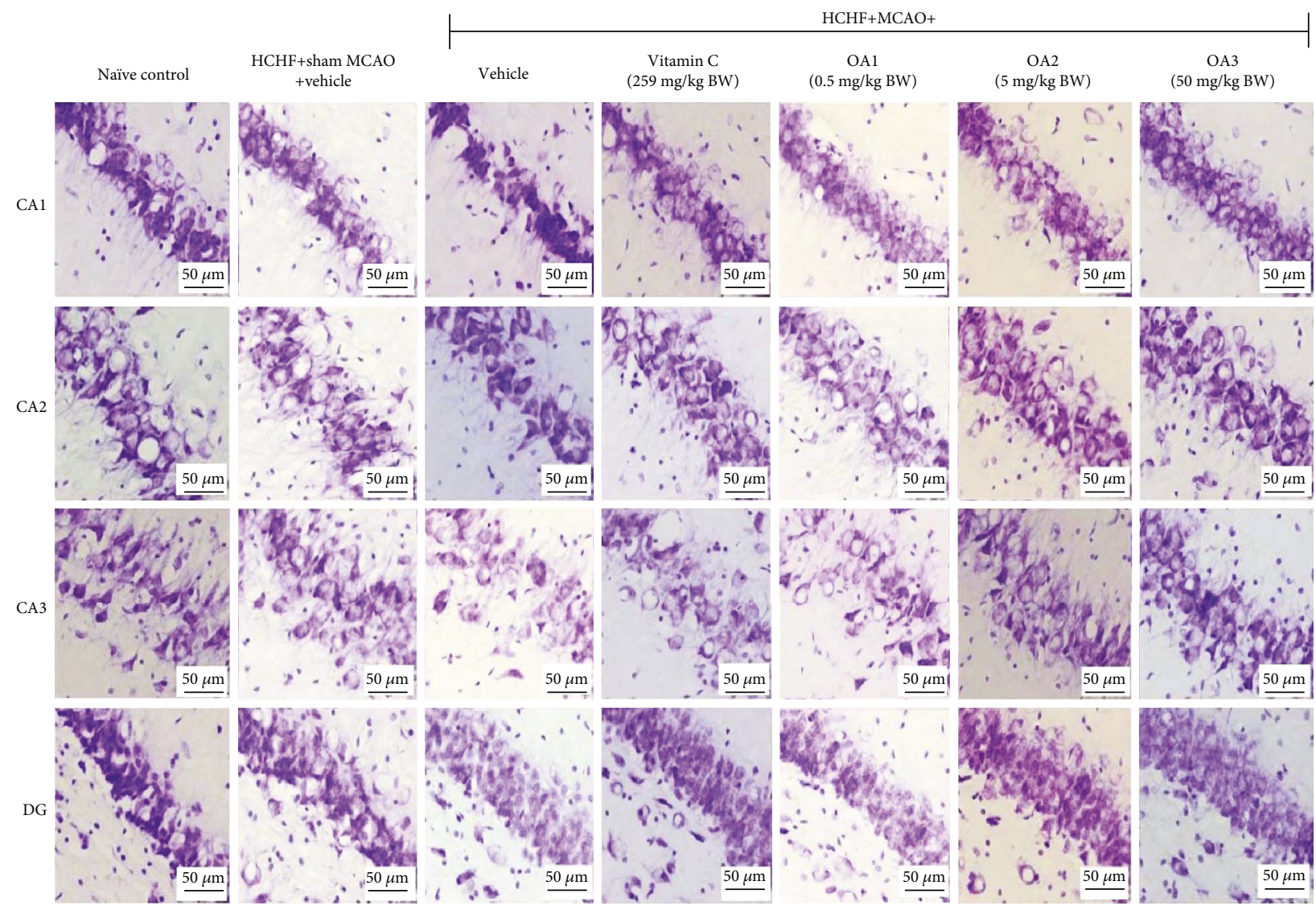

(a)

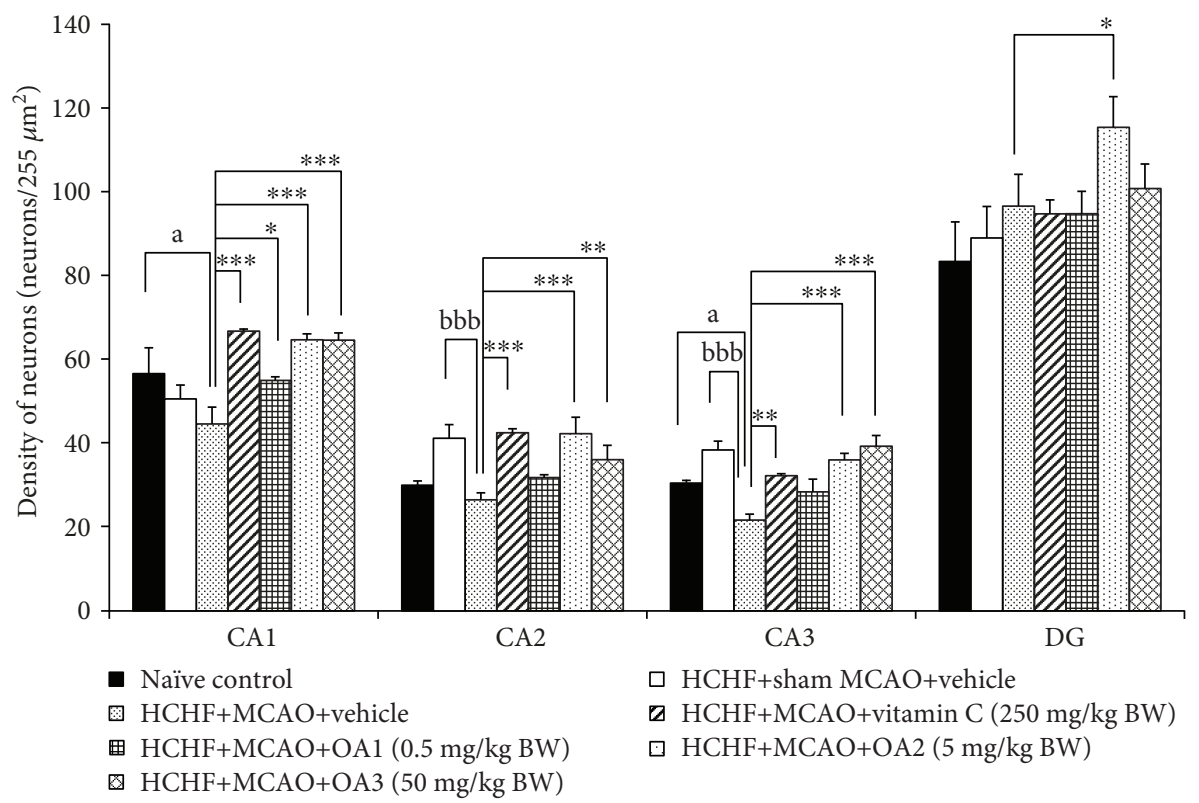

(b)

FIGURE 7: Effect of OA extract on neuron density in various subregions of the hippocampus. (a) Light microscopy of coronal sections in CA1, CA2, CA3, and dentate gyrus of the hippocampus which were stained with cresyl violet at 40x magnification. (b) Density of survival neurons

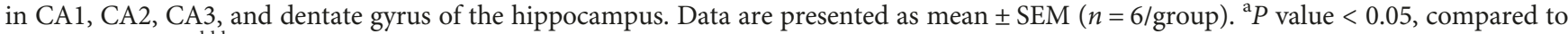
naïve intact rats; ${ }^{\text {bb }} P$ value $<0.001$, compared to sham operation which received HCHF diet and vehicle; and ${ }^{* * *, * * *} P$ value $<0.05,0.01$, and 0.001, respectively, compared to MCAO rats which received HCHF and vehicle. HCHF: high-carbohydrate high-fat diet; MCAO: right middle cerebral artery occlusion; OA1, OA2, and OA3: the combined extract of O. sativa and A. graveolens at doses of 0.5, 5, and $50 \mathrm{mg} / \mathrm{kg}$ BW, respectively. 


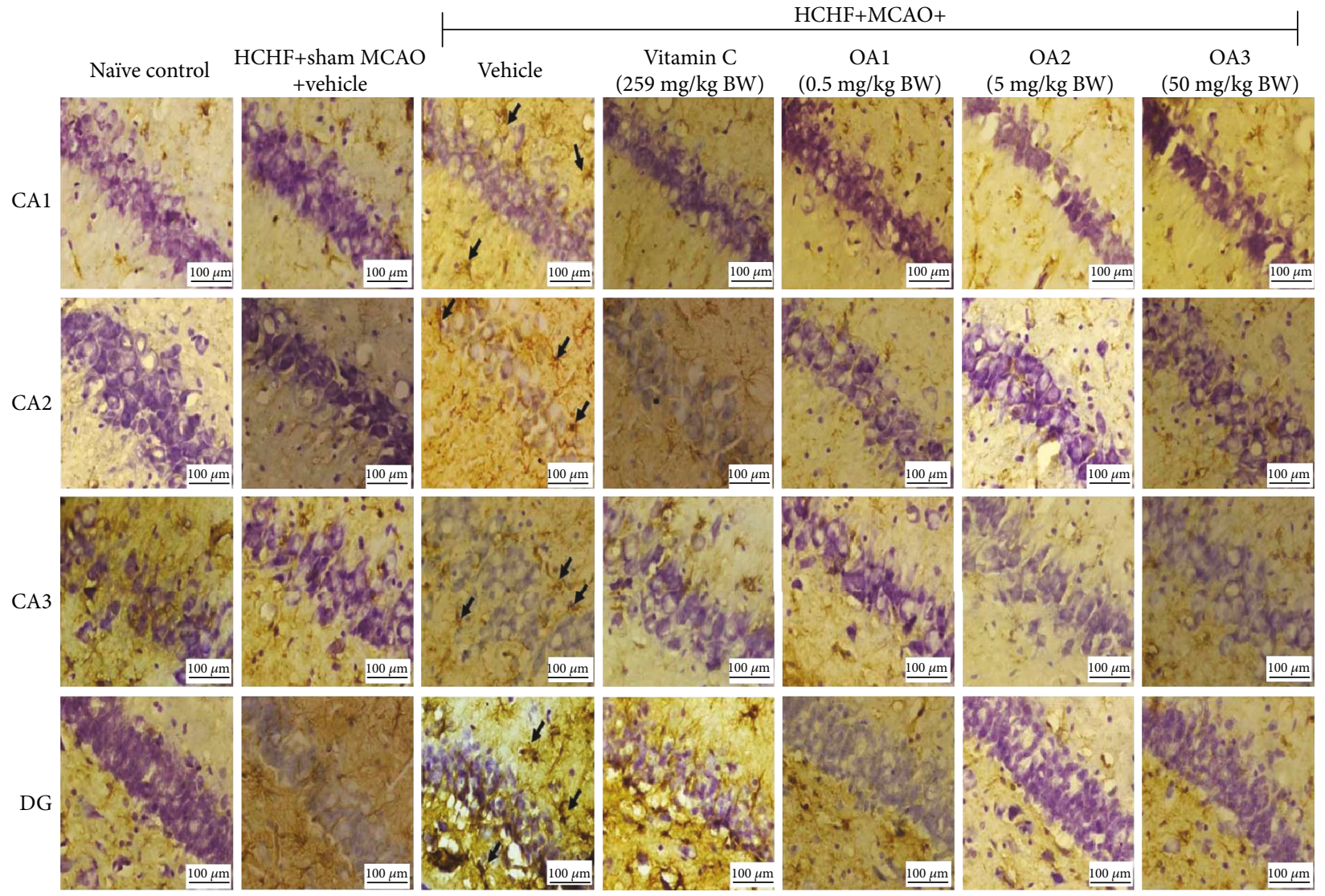

(a)

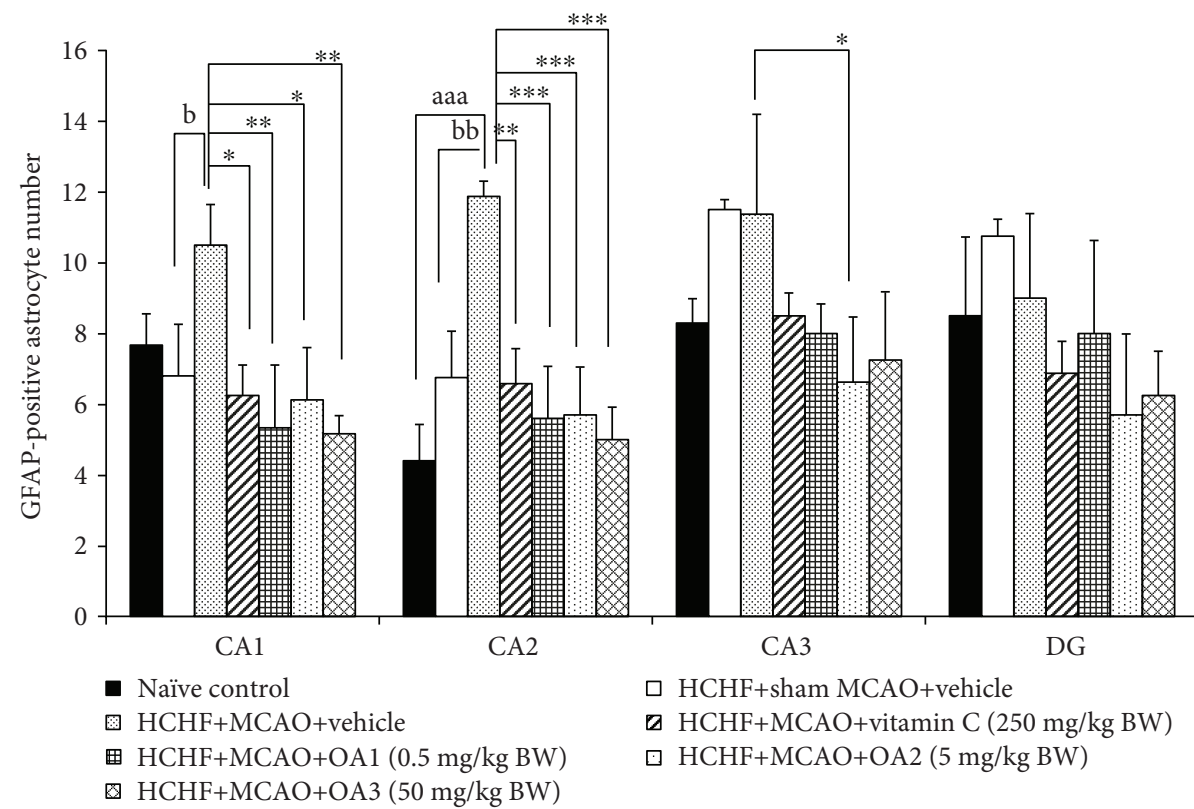

(b)

FIGURE 8: Effect of various doses of OA extract on the density of GFAP-positive cell. (a) Immunostaining for GFAP-positive cell in the hippocampus. GFAP-positive cell or astrocytes were stained brown (arrow). Magnification, 40x; scale bar $=100 \mu \mathrm{m}$. (b) GFAP-positive cells in CA1, CA2, CA3, and dentate gyrus of the hippocampus. Data are presented as mean \pm SEM $(n=6 /$ group). aaa $P$ value $<0.001$, compared to naïve intact rats; ${ }^{\mathrm{b}, \mathrm{bb}} P$ values $<0.05$ and 0.01 , respectively, compared to $\mathrm{HCHF}+\mathrm{MCAO}+$ vehicle; and ${ }^{*, * * * * *} P$ values $<0.05$, 0.01 , and 0.001 , respectively, compared to MCAO rats which received HCHF and vehicle. HCHF: high-carbohydrate high-fat diet; MCAO: right middle cerebral artery occlusion; OA1, OA2, and OA3: the combined extract of O. sativa and A. graveolens at doses of 0.5, 5 , and $50 \mathrm{mg} / \mathrm{kg}$ BW, respectively; GFAP: glial fibrillary acidic protein. 


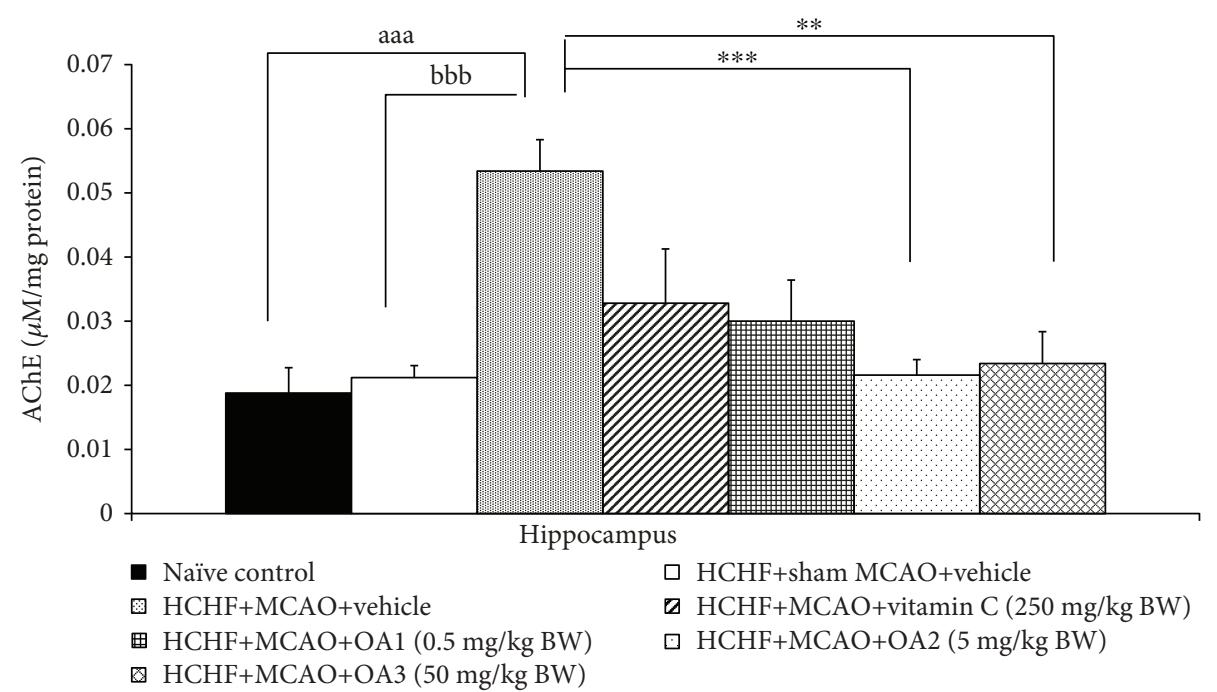

FIgURE 9: The effect of various doses of OA extract on acetylcholinesterase activity in the hippocampus. Data are presented as mean \pm SEM ( $n=6$ /group). ${ }^{\text {aaa }} P$ value $<0.001$, compared to naïve intact rats; ${ }^{\text {bbb }} P$ value $<0.001$, compared to sham operation which received HCHF diet and vehicle; and ${ }^{* * * * *} P$ value $<0.01$ and 0.001 , respectively, compared to MCAO rats which received HCHF and vehicle. HCHF: high-carbohydrate high-fat diet; MCAO: right middle cerebral artery occlusion; OA1, OA2, and OA3: the combined extract of O. sativa and A. graveolens at doses of $0.5,5$, and $50 \mathrm{mg} / \mathrm{kg} \mathrm{BW}$, respectively.

3.3. Histological Changes in the Hippocampus. Since our data demonstrated that OA extract significantly improved spatial memory, the effect of OA extract in the hippocampus, the area contributing an important role on spatial memory [26], was also explored. Figure 7 showed that MCAO significantly decreased neuron density in CA2 and CA3 ( $P$ value $<0.001$ all, compared to the $\mathrm{HCHF}+$ sham operation+vehicle group). Vitamin $\mathrm{C}$ significantly increased neuron densities in CA1, CA2, and CA3 $(P$ value $<0.001$, 0.001 , and 0.01 , respectively, compared to the $\mathrm{HCHF}+$ $\mathrm{MCAO}+$ vehicle group). It was found that the medium dose of OA extract produced the significant increase in neuron densities in CA1, CA2, CA3, and dentate gyrus $(P$ value $<0.001,0.001,0.001$, and 0.05 , respectively, compared to the $\mathrm{HCHF}+\mathrm{MCAO}+$ vehicle group). The low dose of extract significantly increased neuron density in CA1 while the high dose of extract showed the significant increase in neuron density in both CA2 and CA3 ( $P$ value $<0.01$ and 0.001 , respectively, compared to the $\mathrm{HCHF}+\mathrm{MCAO}+$ vehicle group).

Figure 8 showed that a HCHF diet failed to produce the significant changes in GFAP-positive cell in the hippocampus. MCAO significantly enhanced GFAP-positive cell in CA1 and CA2 metabolic syndrome rats $(P$ value $<0.05$ and 0.01 , respectively, compared to the $\mathrm{HCHF}+$ sham operation+vehicle group). Vitamin $\mathrm{C}$ treatment significantly mitigated the changes mentioned earlier $(P$ value $<0.05$ and 0.01 , respectively, compared to the $\mathrm{HCHF}+\mathrm{MCAO}+$ vehicle group). Interestingly, the low and high doses of OA produced the significant reduction of GFAP-positive cell densities in CA1 ( $P$ value $<0.01$ all, compared to the $\mathrm{HCHF}+\mathrm{MCAO}+$ vehicle group) and $\mathrm{CA} 2(P$ value $<0.001$ all, compared to the $\mathrm{HCHF}+\mathrm{MCAO}+$ vehicle group). The medium dose of OA could suppress GFAP-positive cell densities in CA1, CA2, and CA3 ( $P$ value $<0.05,0.001$, and 0.05 , respectively, compared to the $\mathrm{HCHF}+\mathrm{MCAO}+$ vehicle group).

3.4. Effect of OA Extract on Biochemical Parameters. Based on the crucial role of acetylcholinesterase suppression on the memory-enhancing effect $[17,39-43]$, we also determined the effect of OA extract on AChE activity in the hippocampus and data were shown in Figure 9. MCAO significantly enhanced AChE activity in the hippocampus of metabolic syndrome rats induced by a $\mathrm{HCHF}$ diet which received vehicle $(P$ value $<0.001$, compared to the $\mathrm{HCHF}+$ sham operation+vehicle group). However, this change was mitigated by low and medium doses of OA extract $(P$ value $<$ 0.001 and 0.01 , respectively, compared to the $\mathrm{HCHF}+$ $\mathrm{MCAO}+$ vehicle group). Vitamin $\mathrm{C}$ and high dose of $\mathrm{OA}$ extract failed to modulate AChE activity in the hippocampus.

The effect of OA extract on oxidative stress markers including malondialdehyde (MDA), superoxide dismutase (SOD), catalase (CAT), and glutathione peroxidase (GSH-Px) was also determined, and data were shown in Table 2. Sham operation and vehicle failed to produce the significant changes of the aforementioned parameters. MCAO significantly decreased SOD and GSH-Px activities but increased the MDA level $(P$ value $<0.01,0.001$, and 0.001 , respectively, compared to the $\mathrm{HCHF}+$ sham operation+vehicle group). Vitamin $\mathrm{C}$ mitigated the reduction of GSH-Px and the increase in the MDA level in metabolic syndrome rats subjected to MCAO ( $P$ value $<0.001$ all, compared to the $\mathrm{HCHF}+\mathrm{MCAO}+$ vehicle group). All doses of OA extract produced the significant reduction in the MDA level in metabolic syndrome rats with cerebral ischemia $(P$ value $<0.001$ all, compared to the $\mathrm{HCHF}+\mathrm{MCAO}+$ vehicle group). However, the significant increase in SOD and GSH-Px activities was observed only in metabolic syndrome rats with cerebral ischemia which received $\mathrm{OA}$ 
TABLE 2: The effect of various doses of OA extract on oxidative stress markers in the hippocampus.

\begin{tabular}{lcccc}
\hline Treatment group & $\begin{array}{c}\text { MDA level } \\
\text { (ng/mg protein) }\end{array}$ & $\begin{array}{c}\text { SOD activity } \\
\text { (units/mg protein) }\end{array}$ & $\begin{array}{c}\text { CAT activity } \\
\text { (units/mg protein) }\end{array}$ & $\begin{array}{c}\text { GSH-Px activity } \\
\text { (units/mg protein) }\end{array}$ \\
\hline Naïve control & $0.16 \pm 0.02$ & $8.86 \pm 1.52$ & $4.81 \pm 0.69$ & $8.54 \pm 0.59$ \\
HCHF+sham MCAO+vehicle & $0.15 \pm 0.04$ & $8.73 \pm 1.79$ & $2.52 \pm 0.88$ & $10.37 \pm 2.41$ \\
HCHF+MCAO+vehicle & $0.89 \pm 0.10^{\text {aaa,bbb }}$ & $4.73 \pm 0.48^{\text {aa,bb }}$ & $0.62 \pm 0.03^{\text {aaa }}$ & $3.77 \pm 0.26^{\text {aa,bbb }}$ \\
HCHF+MCAO+vitamin C (250 mg/kg BW) & $0.37 \pm 0.08^{* * *}$ & $7.47 \pm 0.59$ & $1.94 \pm 0.50$ & $6.25 \pm 0.66^{* * *}$ \\
HCHF+MCAO+OA1 (0.5 mg/kg BW) & $0.37 \pm 0.06^{* * *}$ & $6.83 \pm 0.19$ & $1.45 \pm 0.21$ & $5.60 \pm 0.87$ \\
HCHF+MCAO+OA2 (5 mg/kg BW) & $0.15 \pm 0.02^{* * *}$ & $5.01 \pm 0.40$ & $1.67 \pm 0.25$ & $8.87 \pm 0.46$ \\
HCHF+MCAO+OA3 (50 mg/kg BW) & $0.25 \pm 0.07^{* * *}$ & $8.01 \pm 1.48^{*}$ & $2.27 \pm 0.27$ & $8.54 \pm 0.59^{* *}$ \\
\hline
\end{tabular}

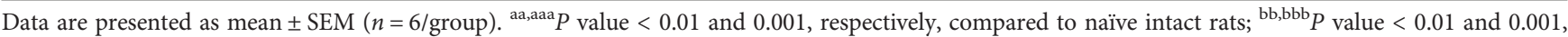
respectively, compared to sham operation which received HCHF diet and vehicle; and ${ }^{* * * * * * *} P$ value $<0.05,0.01$, and 0.001 , respectively, compared to MCAO rats which received HCHF and vehicle.

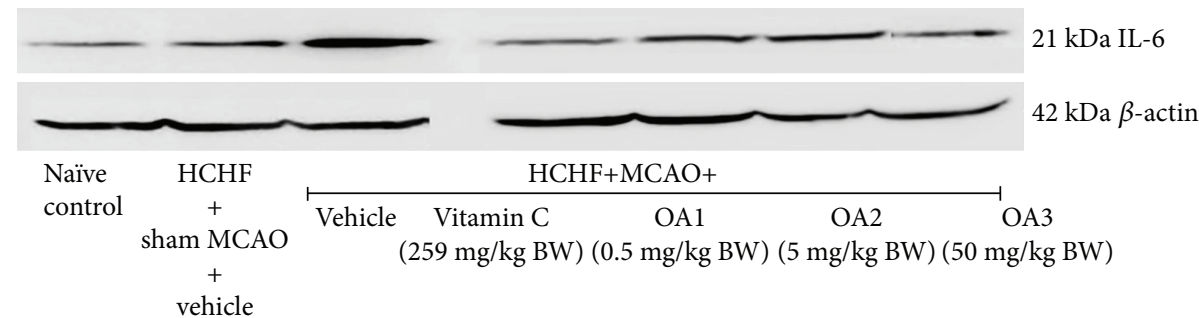

(a)

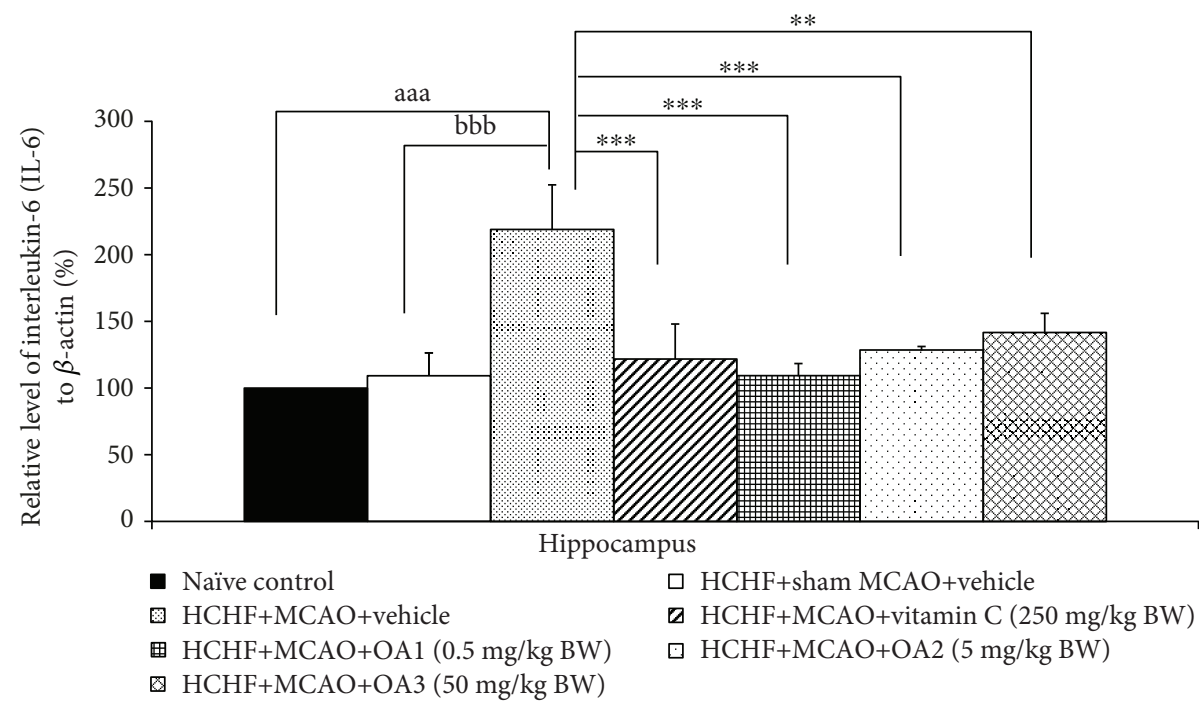

(b)

FIgURE 10: Effect of various doses of OA extract on the expression of IL-6 in the hippocampus. (a) Representative western blot showing the levels of IL-6. (b) Relative density of IL-6. Data are presented as mean \pm SEM ( $n=6 /$ group). aaa $P$ value $<0.001$, compared to naïve

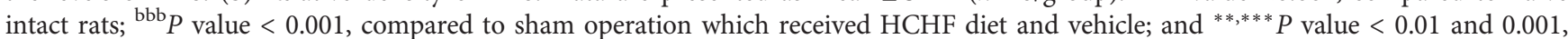
respectively, compared to MCAO rats which received HCHF and vehicle. HCHF: high-carbohydrate high-fat diet; MCAO: right middle cerebral artery occlusion; OA1, OA2, and OA3: the combined extract of O. sativa and A. graveolens at doses of $0.5,5$, and $50 \mathrm{mg} / \mathrm{kg}$ BW, respectively.

extract at dose of $50 \mathrm{mg} / \mathrm{kg} \mathrm{BW}(P$ value $<0.05$ and 0.01 , respectively, compared to the $\mathrm{HCHF}+\mathrm{MCAO}+$ vehicle group).

In addition, sham operation failed to produce the significant change of interleukin-6 (IL-6) and tumor necrosis factor- $\alpha$ (TNF- $\alpha)$ levels in metabolic syndrome rats with cerebral ischemia but MCAO significantly increased the levels of both substances mentioned earlier in the hippocampus $(P$ value $<0.001$ all, compared to the HCHF+sham operation+vehicle group). These changes were mitigated by 


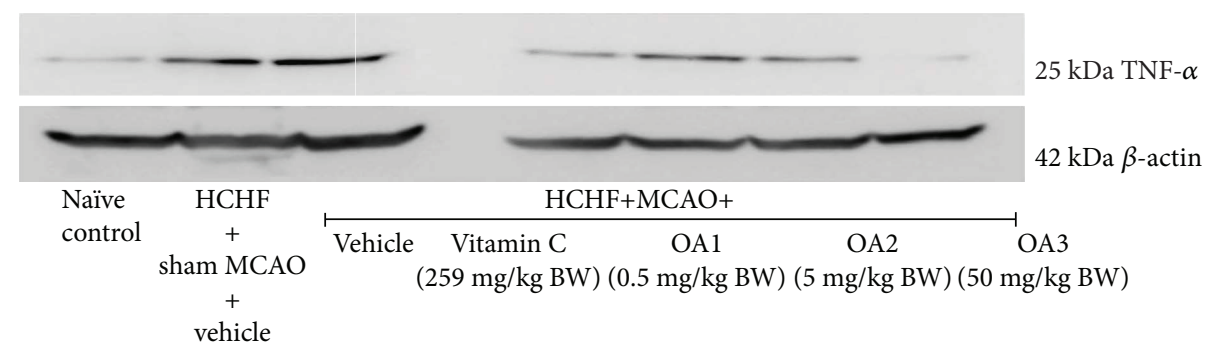

(a)

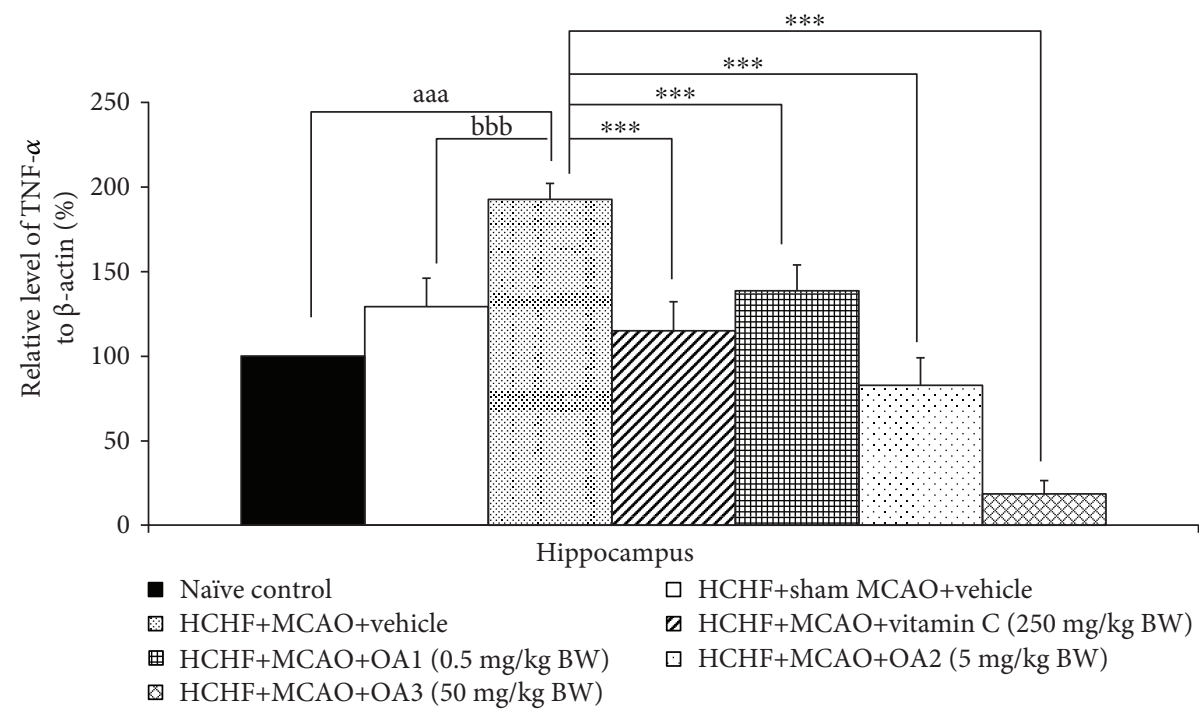

(b)

FIGURE 11: Effect of various doses of OA extract on the expressions of TNF- $\alpha$ in the hippocampus. (a) Representative western blot showing the levels of TNF- $\alpha$. (b) Relative density of TNF- $\alpha$. Data are presented as mean \pm SEM ( $n=6$ /group). ${ }^{\text {aaa }} P$ value $<0.001$, compared to naïve intact rats; ${ }^{\text {bbb }} P$ value $<0.001$, compared to sham operation which received HCHF diet and vehicle; and ${ }^{* * *} P$ value $<0.001$, compared to MCAO rats which received HCHF and vehicle. HCHF: high-carbohydrate high-fat diet; MCAO: right middle cerebral artery occlusion; OA1, OA2, and OA3: the combined extract of O. sativa and A. graveolens at doses of $0.5,5$, and $50 \mathrm{mg} / \mathrm{kg} \mathrm{BW}$, respectively.

vitamin $\mathrm{C}$ and all doses of $\mathrm{OA}$ extract as shown in Figures 10 and 11 .

\section{Discussion}

The current data clearly demonstrated that MetS rats induced by a HCHF diet failed to produce a significant increase in the MDA level and no significant reduction in antioxidant enzyme activities was observed in the hippocampus. In addition, no significant changes in TNF- $\alpha$, IL-6, and hippocampal damage in various regions were observed. Reperfusion after cerebral ischemia (R/I) in MetS rats increased MDA, TNF- $\alpha$, and IL- 6 levels, but it decreased the activities of the main scavenger enzymes including SOD, CAT, and GSH-Px and neuron densities in CA2 and CA3 subregions of the hippocampus. These findings were in agreement with the previous studies which showed that $\mathrm{R} / \mathrm{I}$ enhanced oxidative stress [44] which in turn destroyed the hippocampus, an area playing an important role in learning and memory $[45,46]$ leading to memory impairment [47]. It has been found that vitamin $\mathrm{C}$ and all doses of OA significantly decreased the MDA level, an oxidative stress damage biomarker. However, no tight association between the concentrations of OA used in this study, and the alterations of antioxidant enzyme activities were observed. Although the reduction of the MDA level was observed at all doses used in this study, the elevation of antioxidant enzyme activity was observed only at high dose of OA. These data suggested that other factors might play a role on the reduction of oxidative stress. The recent study has demonstrated that the anthocyanins can act as antioxidant and remove the oxidative stress reactive species produced during reperfusion injury directly [48]. It also enhances glutathione but decreases the MDA level together with the increase in spatial memory [49]. In addition, it can also improve mitochondrial function leading to the reduction of oxidative stress production [50]. Based on the aforementioned effect of $\mathrm{OA}$ on oxidative stress changes and the positive modulation effect of anthocyanins mentioned earlier, we do suggest that the reduction of oxidative stress observed in this study may be explained partly via the direct antioxidant effect of anthocyanins in OA and the elevation of GSH-Px activity which in turn induces the reduction of the MDA level induced by anthocyanins. In addition, the effect to improve 




FIGURE 12: The possible underlying mechanism for the neuroprotective and cognitive enhancing effects of the combined extract of Oryza sativa, L. indica, and Anethum graveolens Linn. (OA extract) in an animal model of metabolic syndrome with cerebral ischemic stroke.

mitochondria functions induced by anthocyanins may also contribute a role on the reduction of oxidative stress observed in this study.

In addition to the oxidative stress, neuroinflammation also plays the role on the brain damage and memory deficit following ischemic injury [51]. Our data also showed that reperfusion injury following cerebral ischemia in metabolic syndrome rats increased TNF- $\alpha$ and IL- 6 together with the cognitive impairment which were in agreement with the previous study [51-53]. After injury, injured neurons in the core and penumbra of the lesion and glial cells in the core produce proinflammatory mediators, cytokines, and reactive oxygen species, which activate both astrocytes and microglia [54]. Then, activated astrocytes can produce the proinflammatory cytokines including IL-6, TNF $\alpha$, and others $[55,56]$. The elevations of cytokines produce the detrimental effect to brain by inducing apoptosis and suppressing the hippocampal neurogenesis $[57,58]$. However, the brain damage and the neuroinflammation can be attenuated by anthocyanins $[59,60]$. In addition, anthocyanins can also decrease neuroinflammation and the density of GFAP-positive cell in the hippocampus and improve memory dysfunction [61]. In addition, our data also showed that OA suppressed AChE in the hippocampus of metabolic syndrome rats.

Based on all data mentioned earlier, we suggest that anthocyanins present in OA may exert the beneficial effect at multitarget sites. Anthocyanins may improve oxidative stress in the hippocampus via the increase in GSH-Px activity and the direct antioxidant effect of anthocyanins. The reduction in the oxidative stress production by mitochondria may also contribute the role, but this part still required a further investigation. In addition, anthocyanins in $\mathrm{OA}$ can also decrease glial cell expression in the hippocampus resulting in the decrease in neuroinflammation leading to the increase in neurogenesis in various subregions of the hippocampus. Therefore, the density of functional neurons in the hippocampus increases giving rise to the improvement of memory performance. Since both glial cell expression and neurogenesis are under the influence of the growth factor, it is possible that anthocyanins can exert the effect to modulate the expression of the growth factor which in turn decreases GFAP-positive cell or glial cell especially astrocyte but enhances neurogenesis in the hippocampus. However, this requires further exploration. Moreover, OA also suppresses $\mathrm{AChE}$ activity in the hippocampus which in turn enhances an available ACh giving rise to the memory enhancement.

\section{Conclusion}

The current study clearly demonstrates that the combined extract of $O$. sativa and A. graveolens or $\mathrm{OA}$ is the functional ingredient to improve cognitive deficit following ischemic stroke in metabolic syndrome condition. The possible underlying mechanisms involve multitargets including the reduction of oxidative stress and neuroinflammation levels together with the suppression of $\mathrm{AChE}$ activity. Interestingly, $\mathrm{OA}$ also possesses neurotrophic effect and suppresses the expression of GFAP-positive cell in the hippocampus as shown in Figure 12. Based on the modulation effects of $\mathrm{OA}$ on various proteins mentioned earlier, the epigenetic modulation effect induced by $\mathrm{OA}$ is worth for further exploration. 


\section{Data Availability}

I confirm that data are available and will be provided on request because during this period, all data are in the process of petty patent registration.

\section{Conflicts of Interest}

The authors declare that they have no conflicts of interest.

\section{Acknowledgments}

This study was supported by the Integrative Complementary Alternative Medicine Research and Development Center in Research Institute for Human High Performance and Health Promotion, Khon Kaen University, Khon Kaen, Thailand, Invitation Research Grant of Faculty of Medicine, and Graduate School of Khon Kaen University (Grant number IN59126).

\section{References}

[1] R. J. Adams, S. Appleton, D. H. Wilson et al., "Population comparison of two clinical approaches to the metabolic syndrome: implications of the new International Diabetes Federation consensus definition," Diabetes Care, vol. 28, no. 11, pp. 2777-2779, 2005.

[2] P. B. Nolan, G. Carrick-Ranson, J. W. Stinear, S. A. Reading, and L. C. Dalleck, "Prevalence of metabolic syndrome and metabolic syndrome components in young adults: a pooled analysis," Preventive Medicine Reports, vol. 7, pp. 211-215, 2017.

[3] J. K. Ninomiya, G. L'Italien, M. H. Criqui, J. L. Whyte, A. Gamst, and R. S. Chen, "Association of the metabolic syndrome with history of myocardial infarction and stroke in the Third National Health and Nutrition Examination Survey," Circulation, vol. 109, no. 1, pp. 42-46, 2004.

[4] H. J. Milionis, E. Rizos, J. Goudevenos, K. Seferiadis, D. P. Mikhailidis, and M. S. Elisaf, "Components of the metabolic syndrome and risk for first-ever acute ischemic nonembolic stroke in elderly subjects," Stroke, vol. 36, no. 7, pp. 13721376, 2005.

[5] S.-H. Suk, R. L. Sacco, B. Boden-Albala et al., "Abdominal obesity and risk of ischemic stroke. The Northern Manhattan Stroke Study," Stroke, vol. 34, no. 7, pp. 1586-1592, 2003.

[6] N. Koren-Morag, U. Goldbourt, and D. Tanne, "Relation between the metabolic syndrome and ischemic stroke or transient ischemic attack: a prospective cohort study in patients with atherosclerotic cardiovascular disease," Stroke, vol. 36, no. 7, pp. 1366-1371, 2005.

[7] R. M. Najarian, L. M. Sullivan, W. B. Kannel, P. W. Wilson, R. B. D'Agostino, and P. A. Wolf, "Metabolic syndrome compared with type 2 diabetes mellitus as a risk factor for stroke: the Framingham Offspring Study," Archives of Internal Medicine, vol. 166, no. 1, pp. 106-111, 2006.

[8] H. J. Chen, C. H. Bai, W. T. Yeh, H. C. Chiu, and W. H. Pan, "Influence of metabolic syndrome and general obesity on the risk of ischemic stroke," Stroke, vol. 37, no. 4, pp. 1060-1064, 2006.

[9] S. Kurl, J. A. Laukkanen, L. Niskanen et al., "Metabolic syndrome and the risk of stroke in middle-aged men," Stroke, vol. 37, no. 3, pp. 806-811, 2006.
[10] G. Nys, M. van Zandvoort, P. de Kort, B. Jansen, L. Kappelle, and E. de Haan, "Restrictions of the Mini-Mental State Examination in acute stroke," Archives of Clinical Neuropsychology, vol. 20, no. 5, pp. 623-629, 2005.

[11] M. Muriach, M. Flores-Bellver, F. J. Romero, and J. M. Barcia, "Diabetes and the brain: oxidative stress, inflammation, and autophagy," Oxidative Medicine and Cellular Longevity, vol. 2014, Article ID 102158, 9 pages, 2014.

[12] A. Sarkaki, M. Rafieirad, S. E. Hossini et al., "Improvement in memory and brain long-term potentiation deficits due to permanent hypoperfusion/ischemia by grape seed extract in rats," Iranian Journal of Basic Medical Sciences, vol. 16, no. 9, pp. 1004-1010, 2013.

[13] K. Basinska, K. Marycz, A. Śmieszek, and J. Nicpoń, “The production and distribution of IL- 6 and TNF- $\alpha$ in subcutaneous adipose tissue and their correlation with serum concentrations in Welsh ponies with equine metabolic syndrome," Journal of Veterinary Science, vol. 16, no. 1, pp. 113-120, 2015.

[14] C. Cetin, A. M. Erdogan, G. C. Dincel, B. Bakar, and U. Kisa, "Effects of sulphasalazine in cerebral ischemia reperfusion injury in rat," Archives of Medical Research, vol. 48, no. 3, pp. 247-256, 2017.

[15] D.-H. Choi and J. Lee, "A mini-review of the NADPH oxidases in vascular dementia: correlation with NOXs and risk factors for $\mathrm{VaD}$," International Journal of Molecular Sciences, vol. 18, no. 11, p. 2500, 2017.

[16] Ö. Karadaş, G. Koç, A. Ö. Özön, B. Öztürk, and D. Konukoğlu, "Biomarkers of Alzheimer's disease and vascular dementia simultaneously sampled from serum and cerebrospinal fluid," Turkish Journal of Geriatrics, vol. 20, no. 1, pp. 1-7, 2017.

[17] S. Kawvised, J. Wattanathorn, and W. Thukham-mee, "Neuroprotective and cognitive-enhancing effects of microencapsulation of mulberry fruit extract in animal model of menopausal women with metabolic syndrome," Oxidative Medicine and Cellular Longevity, vol. 2017, Article ID 2962316, 13 pages, 2017.

[18] D. Vauzour, M. Camprubi-Robles, S. Miquel-Kergoat et al., "Nutrition for the ageing brain: towards evidence for an optimal diet," Ageing Research Reviews, vol. 35, pp. 222-240, 2017.

[19] X. Xia, W. Ling, J. Ma et al., "An anthocyanin-rich extract from black rice enhances atherosclerotic plaque stabilization in apolipoprotein E-deficient mice," The Journal of Nutrition, vol. 136, no. 8, pp. 2220-2225, 2006.

[20] R. Yazdanparast and S. Bahramikia, "Evaluation of the effect of Anethum graveolens L. crude extracts on serum lipids and lipoproteins profiles in hypercholesterolaemic rats," DARU Journal of Pharmaceutical Sciences, vol. 16, pp. 88-94, 2008.

[21] P. Limtrakul, S. Yodkeeree, P. Pitchakarn, and W. Punfa, "Anti-inflammatory effects of proanthocyanidin-rich red rice extract via suppression of MAPK, AP-1 and NF- $\kappa$ B pathways in Raw 264.7 macrophages," Nutrition Research and Practice, vol. 10, no. 3, pp. 251-258, 2016.

[22] L. Payahoo, A. Ostadrahimi, M. Mobasseri et al., "Anethum graveolens L. supplementation has anti-inflammatory effect in type 2 diabetic patients," Indian Journal of Traditional Knowledge, vol. 13, no. 3, pp. 461-465, 2014.

[23] W. Pannangrong, J. Wattanathorn, S. Muchimapura, S. Tiamkao, and T. Tong-Un, "Purple rice berry is neuroprotective and enhances cognition in a rat model of Alzheimer's disease," Journal of Medicinal Food, vol. 14, no. 7-8, pp. 688694, 2011. 
[24] A. Mesripour, M. Rafieian-Kopaei, and B. Bahrami, "The effects of Anethum graveolens essence on scopolamine-induced memory impairment in mice," Research in Pharmaceutical Sciences, vol. 11, no. 2, pp. 145-151, 2016.

[25] W. Thukham-mee and J. Wattanathorn, "Evaluation of safety and protective effect of combined extract of Cissampelos pareira and Anethum graveolens (PM52) against age-related cognitive impairment," Evidence-Based Complementary and Alternative Medicine, vol. 2012, Article ID 674101, 10 pages, 2012.

[26] C. Kaur and H. C. Kapoor, "Anti-oxidant activity and total phenolic content of some Asian vegetables," International Journal of Food Science and Technology, vol. 37, no. 2, pp. 153-161, 2002.

[27] A. Luximon-Ramma, T. Bahorun, M. A. Soobrattee, and O. I. Aruoma, "Antioxidant activities of phenolic, proanthocyanidin, and flavonoid components in extracts of Cassia fistula," Journal of Agricultural and Food Chemistry, vol. 50, no. 18, pp. 5042-5047, 2002.

[28] B. De Ancos, S. Sgroppo, L. Plaza, and M. P. Cano, "Possible nutritional and health-related value promotion in orange juice preserved by high-pressure treatment," Journal of the Science of Food and Agriculture, vol. 82, no. 8, pp. 790-796, 2002.

[29] M. A. Ebrahimzadeh, S. J. Hosseinimehr, A. Hamidinia, and M. Jafari, "Antioxidant and free radical scavenging activity of Feijoa sellowiana fruits peel and leaves," Pharmacologyonline, vol. 1, pp. 7-14, 2008.

[30] N. J. Miller, C. Rice-Evans, M. J. Davies, V. Gopinathan, and A. Milner, "A novel method for measuring antioxidant capacity and its application to monitoring the antioxidant status in premature neonates," Clinical Science, vol. 84, no. 4, pp. 407-412, 1993.

[31] G. L. Ellman, K. D. Courtney, V. Andres Jr., and R. M. Featherstone, "A new and rapid colorimetric determination of acetylcholinesterase activity," Biochemical Pharmacology, vol. 7, no. 2, pp. 88-95, 1961.

[32] H. Cho, C. W. Yun, W. K. Park et al., "Modulation of the activity of pro-inflammatory enzymes, COX-2 and iNOS, by chrysin derivatives," Pharmacological Research, vol. 49, no. 1, pp. 37-43, 2004.

[33] D. F. García-Díaz, J. Campion, F. I. Milagro, A. Lomba, F. Marzo, and J. A. Martínez, "Chronic mild stress induces variations in locomotive behavior and metabolic rates in high fat fed rats," Journal of Physiology and Biochemistry, vol. 63, no. 4, pp. 337-346, 2007.

[34] H. Ohkawa, N. Ohishi, and K. Yagi, “Assay for lipid peroxides in animal tissues by thiobarbituric acid reaction," Analytical Biochemistry, vol. 95, no. 2, pp. 351-358, 1979.

[35] M. B. Harishekar and B. Kiran, "Studies on lipid peroxidation induced by lead, alcohol on liver and amelioration by vitamin E," Asian Journal of Pharmaceutical and Clinical Research, vol. 4, no. 2, pp. 164-167, 2011.

[36] Y. Sun, L. W. Oberley, and Y. Li, "A simple method for clinical assay of superoxide dismutase," Clinical Chemistry, vol. 34, no. 3, pp. 497-500, 1988.

[37] S. A. Goldblith and B. E. Proctor, "Photometric determination of catalase activity," Journal of Biological Chemistry, vol. 187, no. 2, pp. 705-709, 1950.

[38] P. Eyer and D. Podhradský, "Evaluation of the micromethod for determination of glutathione using enzymatic cycling and
Ellman's reagent," Analytical Biochemistry, vol. 153, no. 1, pp. 57-66, 1986.

[39] Y. Shrager, P. J. Bayley, B. Bontempi, R. O. Hopkins, and L. R. Squire, "Spatial memory and the human hippocampus," Proceedings of the National Academy of Sciences of the United States of America, vol. 104, no. 8, pp. 2961-2966, 2007.

[40] W. Kirisattayakul, J. Wattanathorn, S. Iamsaard, J. Jittiwat, B. Suriharn, and K. Lertrat, "Neuroprotective and memory-enhancing effect of the combined extract of purple waxy corn cob and pandan in ovariectomized rats," Oxidative Medicine and Cellular Longevity, vol. 2017, Article ID 5187102, 12 pages, 2017.

[41] N. Phunchago, J. Wattanathorn, and K. Chaisiwamongkol, "Tiliacora triandra, an anti-intoxication plant, improves memory impairment, neurodegeneration, cholinergic function, and oxidative stress in hippocampus of ethanol dependence rats," Oxidative Medicine and Cellular Longevity, vol. 2015, Article ID 918426, 9 pages, 2015.

[42] C. Sutalangka, J. Wattanathorn, S. Muchimapura, and W. Thukham-mee, "Moringa oleifera mitigates memory impairment and neurodegeneration in animal model of age-related dementia," Oxidative Medicine and Cellular Longevity, vol. 2013, Article ID 695936, 9 pages, 2013.

[43] C. Sutalangka and J. Wattanathorn, "Neuroprotective and cognitive-enhancing effects of the combined extract of Cyperus rotundus and Zingiber officinale," BMC Complementary and Alternative Medicine, vol. 17, no. 1, p. 135, 2017.

[44] H. Chen, H. Yoshioka, G. S. Kim et al., "Oxidative stress in ischemic brain damage: mechanisms of cell death and potential molecular targets for neuroprotection," Antioxidants \& Redox Signaling, vol. 14, no. 8, pp. 1505-1517, 2011.

[45] F. Dal-Pizzol, F. Klamt, M. L. C. Frota Jr. et al., "Neonatal iron exposure induces oxidative stress in adult Wistar rat," Developmental Brain Research, vol. 130, no. 1, pp. 109-114, 2001.

[46] F. Dal-Pizzol, F. Klamt, M. M. R. Vianna et al., "Lipid peroxidation in hippocampus early and late after status epilepticus induced by pilocarpine or kainic acid in Wistar rats," Neuroscience Letters, vol. 291, no. 3, pp. 179-182, 2000.

[47] H. L. Schimidt, A. Vieira, C. Altermann et al., "Memory deficits and oxidative stress in cerebral ischemia-reperfusion: neuroprotective role of physical exercise and green tea supplementation," Neurobiology of Learning and Memory, vol. 114, pp. 242-250, 2014.

[48] R. L. Prior and X. Wu, “Anthocyanins: structural characteristics that result in unique metabolic patterns and biological activities," Free Radical Research, vol. 40, no. 10, pp. 10141028, 2006.

[49] P. Kaewkaen, T. Tong-un, J. Wattanathorn, S. Muchimapura, W. Kaewrueng, and S. Wongcharoenwanakit, "Mulberry fruit extract protects against memory impairment and hippocampal damage in animal model of vascular dementia," Evidence-Based Complementary and Alternative Medicine, vol. 2012, Article ID 263520, 9 pages, 2012.

[50] K. Skemiene, J. Liobikas, and V. Borutaite, "Anthocyanins as substrates for mitochondrial complex I-protective effect against heart ischemic injury," The FEBS Journal, vol. 282, no. 5, pp. 963-971, 2015.

[51] B. Silva, L. Sousa, A. Miranda et al., "Memory deficit associated with increased brain proinflammatory cytokine levels and neurodegeneration in acute ischemic stroke," Arquivos de Neuro-Psiquiatria, vol. 73, no. 8, pp. 655-659, 2015. 
[52] S. Chen, Z. J. Yin, C. Jiang et al., “Asiaticoside attenuates memory impairment induced by transient cerebral ischemiareperfusion in mice through anti-inflammatory mechanism," Pharmacology Biochemistry and Behavior, vol. 122, pp. 7-15, 2014.

[53] C. Murray, D. J. Sanderson, C. Barkus et al., "Systemic inflammation induces working memory deficit in the primed brain: relevance for delirium," Neurobiology of Aging, vol. 33, no. 3, pp. 603-616.e3, 2012.

[54] A. Tuttolomondo, D. Di Raimondo, R. di Sciacca, A. Pinto, and G. Licata, "Inflammatory cytokines in acute ischemic stroke," Current Pharmaceutical Design, vol. 14, no. 33, pp. 3574-3589, 2008.

[55] L. T. Lau and A. C. H. Yu, "Astrocytes produce and release interleukin-1, interleukin-6, tumor necrosis factor alpha and interferon-gamma following traumatic and metabolic injury," Journal of Neurotrauma, vol. 18, no. 3, pp. 351-359, 2001.

[56] O. Orzylowska, B. Oderfeld-Nowak, M. Zaremba, S. Januszewski, and M. Mossakowski, "Prolonged and concomitant induction of astroglial immunoreactivity of interleukin-1beta and interleukin-6 in the rat hippocampus after transient global ischemia," Neuroscience Letters, vol. 263, no. 1, pp. 72-76, 1999.

[57] L. Vallières, I. L. Campbell, F. H. Gage, and P. E. Sawchenko, "Reduced hippocampal neurogenesis in adult transgenic mice with chronic astrocytic production of interleukin-6," Journal of Neuroscience, vol. 22, no. 2, pp. 486-492, 2002.

[58] G. Stoll, S. Jander, and M. Schroeter, "Inflammation and glial responses in ischemic brain lesions," Progress in Neurobiology, vol. 56, no. 2, pp. 149-171, 1998.

[59] A. M. Amini, K. Muzs, J. P. Spencer, and P. Yaqoob, "Pelargonidin-3-O-glucoside and its metabolites have modest anti-inflammatory effects in human whole blood cultures," Nutrition Research, vol. 46, pp. 88-95, 2017.

[60] H. X. Cui, J. H. Chen, J. W. Li, F. R. Cheng, and K. Yuan, "Protection of anthocyanin from Myrica rubra against cerebral ischemia-reperfusion injury via modulation of the TLR4/NF- $\kappa$ B and NLRP3 pathways," Molecules, vol. 23, no. 7, p. 1788, 2018.

[61] F. B. Carvalho, J. M. Gutierres, A. Bueno et al., "Anthocyanins control neuroinflammation and consequent memory dysfunction in mice exposed to lipopolysaccharide," Molecular Neurobiology, vol. 54, no. 5, pp. 3350-3367, 2017. 


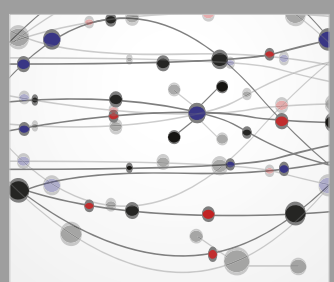

The Scientific World Journal
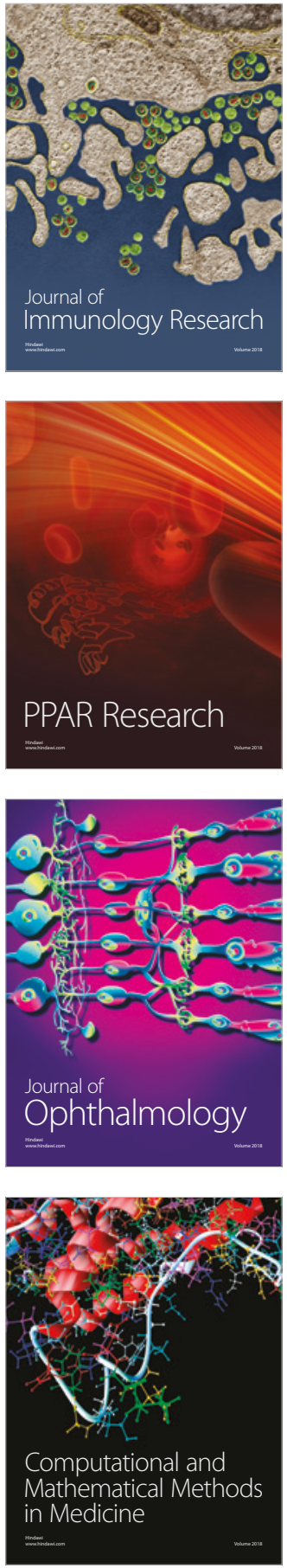

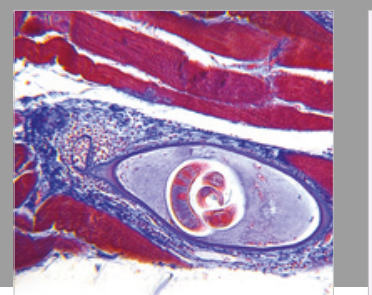

Gastroenterology Research and Practice

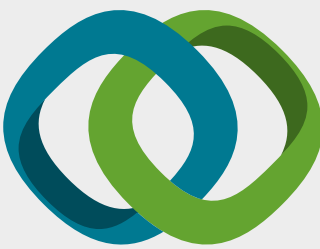

\section{Hindawi}

Submit your manuscripts at

www.hindawi.com
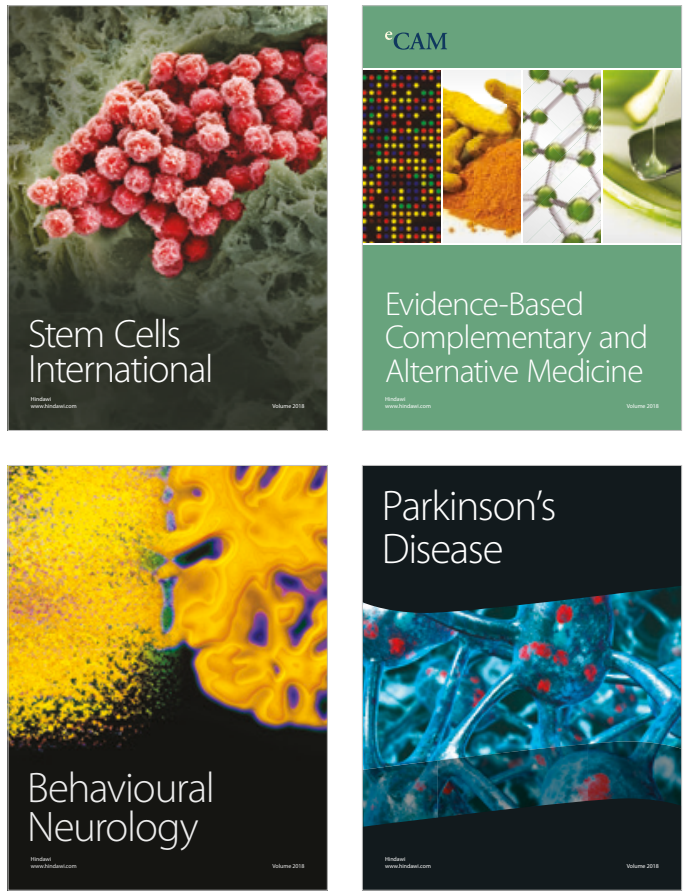

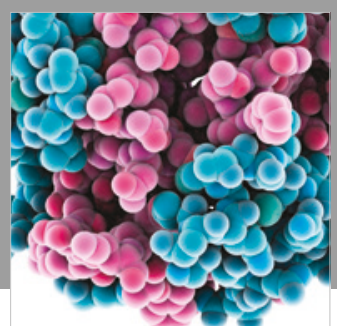

ournal of

Diabetes Research

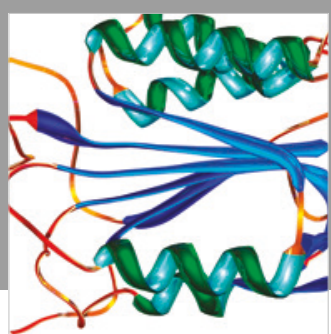

Disease Markers
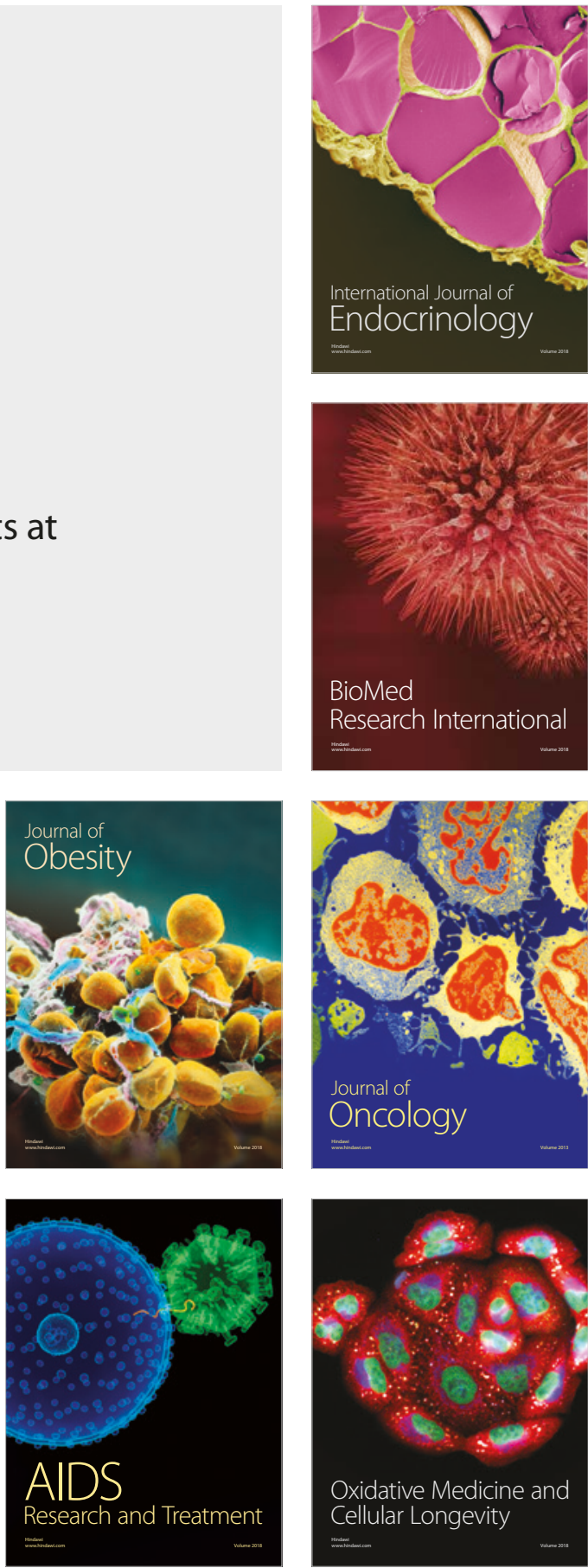